\title{
Revision of the Late Jurassic deep-water teleosauroid crocodylomorph Teleosaurus megarhinus Hulke, 1871 and evidence of pelagic adaptations in Teleosauroidea
}

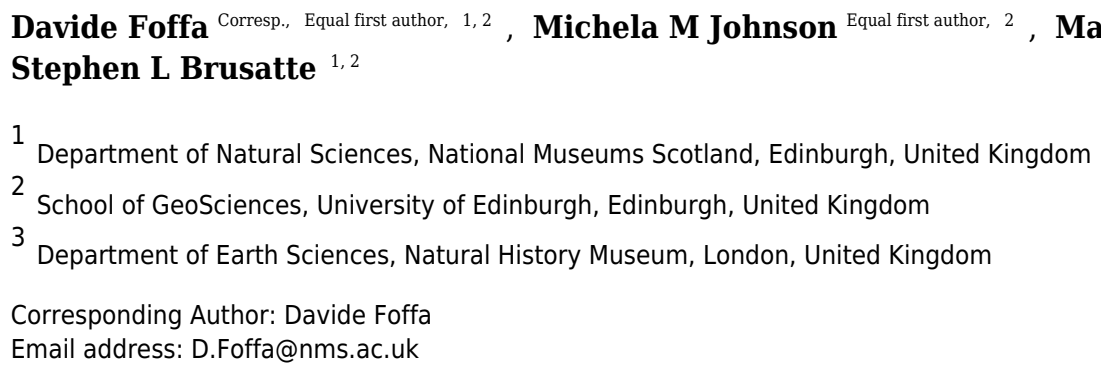

Teleosauroids were a successful group of semi-aquatic crocodylomorphs that were an integral part of coastal marine/lagoonal faunas during the Jurassic. Their fossil record suggests that the group declined in diversity and abundance in deep water deposits during the Late Jurassic. One of the few known teleosauroid species from the deeper water horizons of the well-known Kimmeridge Clay Formation is 'Teleosaurus' megarhinus Hulke, 1871, a poorly studied, gracile longirostrine form. The holotype is an incomplete snout from the Aulacostephanus autissiodorensis Sub-Boreal ammonite Zone of Kimmeridge, England. The only other referred specimen is an almost complete skull from the slightly older A. eudoxus Sub-Boreal ammonite Zone of Quercy, France. Recently, the validity of this species has been called into question. Here we re-describe the holotype as well as the referred French specimen and another incomplete teleosauroid, DORCM G.05067i-v (an anterior rostrum with three osteoderms and an isolated tooth crown), from the same horizon and locality as the holotype. We demonstrate that all specimens are referable to 'Teleosaurus' megarhinus and that the species is indeed a valid taxon, which we assign to a new monotypic genus, Bathysuchus. In our phylogenetic analysis, the latest iteration of the ongoing Crocodylomorph SuperMatrix Project, Bathysuchus megarhinus is found as sister taxon to Aeolodon priscus within a subclade containing Mycterosuchus nasutus and Teleosaurus cadomensis. Notably Bathysuchus has an extreme reduction in dermatocranial ornamentation and osteoderm size, thickness and ornamentation. These features are mirrored in Aeolodon priscus, a species with a well-preserved post-cranial skeleton and a similar shallow and inconspicuous dermal ornamentation. Based on these morphological features, and sedimentological evidence, we hypothesise that the Bathysuchus + Aeolodon clade is the first known teleosauroid lineage that evolved a more pelagic lifestyle. 
1 REVISION OF THE LATE JURASSIC DEEP-WATER TELEOSAUROID

2 CROCODYLOMORPH TELEOSAURUS MEGARHINUS HULKE, 1871 AND EVIDENCE OF

3 PELAGIC ADAPTATIONS IN TELEOSAUROIDEA

4

5

6

7 Davide Foffa, ${ }^{1,2 *}$ Michela M. Johnson, ${ }^{2}$ Mark T. Young, ${ }^{2}$ Lorna Steel, ${ }^{3}$ and Stephen L.

8 Brusatte 2,1

9

$10{ }^{1}$ Department of Natural Sciences, National Museums Scotland, Edinburgh, United Kingdom

$11{ }^{2}$ School of Geosciences, University of Edinburgh, Edinburgh, United Kingdom

$12{ }^{3}$ Department of Earth Sciences, Natural History Museum, London, United Kingdom

13

14

$15{ }^{*}$ Corresponding author: Davide Foffa, davidefoffa@gmail.com; $\underline{\text { d.foffa@nms.ac.uk }}$ 


\section{ABSTRACT}

18 Teleosauroids were a successful group of semi-aquatic crocodylomorphs that were an integral

19 part of coastal marine/lagoonal faunas during the Jurassic. Their fossil record suggests that the group declined in diversity and abundance in deep water deposits during the Late Jurassic. One of the few known teleosauroid species from the deeper water horizons of the well-known Kimmeridge Clay Formation is 'Teleosaurus' megarhinus Hulke, 1871, a poorly studied, gracile longirostrine form. The holotype is an incomplete snout from the Aulacostephanus autissiodorensis Sub-Boreal ammonite Zone of Kimmeridge, England. The only other referred specimen is an almost complete skull from the slightly older $A$. eudoxus Sub-Boreal ammonite Zone of Quercy, France. Recently, the validity of this species has been called into question. Here we re-describe the holotype as well as the referred French specimen and another incomplete teleosauroid, DORCM G.05067i-v (an anterior rostrum with three osteoderms and an isolated tooth crown), from the same horizon and locality as the holotype. We demonstrate that all specimens are referable to 'Teleosaurus' megarhinus and that the species is indeed a valid taxon, which we assign to a new monotypic genus, Bathysuchus. In our phylogenetic analysis, the latest iteration of the ongoing Crocodylomorph SuperMatrix Project, Bathysuchus megarhinus is found as sister taxon to Aeolodon priscus within a subclade containing Mycterosuchus nasutus and Teleosaurus cadomensis. Notably Bathysuchus has an extreme reduction in dermatocranial ornamentation and osteoderm size, thickness and ornamentation. These features are mirrored in Aeolodon priscus, a species with a well-preserved post-cranial skeleton and a similar shallow and inconspicuous dermal ornamentation. Based on these morphological features, and sedimentological evidence, we hypothesise that the Bathysuchus + Aeolodon clade is the first known teleosauroid lineage that evolved a more pelagic lifestyle. 
41

42 Teleosauroids (one of the subgroups of Thalattosuchia) were a successful group of semi-aquatic

43 Jurassic crocodylomorphs. They were abundant in marine/lagoonal faunas for most of the

44

\section{INTRODUCTION}

Jurassic of Europe, Asia and Africa (Andrews 1909; Andrews 1913; Buffetaut et al. 1981;

Lepage et al. 2008; Young et al. 2016; Jouve et al. 2016; Johnson et al. 2018), and continued into the Early Cretaceous of Africa (Fanti et al. 2016). Teleosauroids underwent a severe decline across the Middle-Late Jurassic boundary at Sub-Boreal and Boreal latitudes, but remained numerically and taxonomically abundant in the Late Jurassic of the Tethys and continental Europe (Young et al. 2014, 2014b; Foffa et al. 2015; Johnson et al. 2015; Johnson et al. 2017).

The teleosauroid fossil record is particularly sparse in the Late Jurassic Kimmeridge Clay Formation (KCF; Kimmeridgian-Tithonian, 157-148 Ma) of the UK (Young and Steel 2014), where rare fossilised remains are almost exclusively limited to isolated tooth crowns (NHMUK PV R 1774) and osteoderms (MJML K2158 and BRSMG Ce9826; CAMSM J.29481; OUMNH J.77970-1) (Seeley 1869; Young and Steel, 2014; Foffa et al. 2018). The only exceptions are the cranial remains of an enigmatic longirostrine teleosauroid, 'Teleosaurus' megarhinus, from the deep-water deposits of the Kimmeridgian of Dorset (England, UK) and a shallower (up to 100 m) contemporaneous formation of Franculès (Quercy, France) (Hulke 1871; Delair 1958; Vignaud et al. 1993). The lack of information on this taxon is frustrating, as it not only comes from a well-sampled interval, but it is also one of the few teleosauroids that may have adapted to deeper-water environments, as opposed to the more nearshore ecosystems that most members of the clade inhabited. Thus, 'Teleosaurus' megarhinus may provide pivotal insights into the palaeobiology and evolution of teleosauroids. 
64

65

Hulke, 1871, and describe a new specimen that can also be referred to this taxon (DORCM G.05067i- v). Our description of this material reveals a unique combination of characters that validates the species. With the aid of an updated and expanded teleosauroid phylogenetic dataset, we test the relationships of this species, but find that it does not group with the type species of Teleosaurus, T. cadomensis, but rather within a clade that includes another supposed deep-water teleosauroid. This necessitates the establishment of a new genus name for 'Teleosaurus' megarhinus, and indicates that there was a subclade of teleosauroids adapted to a deeper-water, open-ocean environment during the Jurassic. Along with their purely pelagic cousins, the metriorhynchids, these teleosauroids were an independent thalattosuchian invasion into the marine realm during the Jurassic, revealing previously unrecognized parallelism within this major group of early crocodylomorphs.

\section{Historical background}

The holotype of Teleosaurus megarhinus (NHMUK PV OR 43086) was discovered in the winter of 1870 in the Kimmeridge Clay Formation strata at Kimmeridge Bay (Dorset), in England. J.C. Mansel-Pleydell (a Dorset antiquary, famous for his contribution to geology, botany and zoology) sent the specimen to J.W. Hulke to be described (Hulke 1871; Delair 1958). After making comparisons with other specimens, Hulke assigned the specimen to Teleosaurus (without supporting the decision) and proposed the specific designation megarhinus based on the 'dilation of the terminal nostril' that he considered as 'greater than in any other Teleosaurus known to me' (sic Hulke 1871, pp. 442). Lydekker (1888) later referred the species to the genus Steneosaurus. on its total skull (premaxillary and maxillary) tooth count, and stratigraphic occurrence (Vignaud 
86

87

et al. 1993). Vignaud et al. (1993) also compared 'S.' megarhinus with other longirostrine teleosauroids from the Late Jurassic of Europe (Steneosaurus deslongchampsianus Lennier, 1887 and Aeolodon priscus von Sömmerring, 1814), and considered 'S.' megarhinus to be a valid taxon, but they were only able to differentiate these three species based on tooth counts. Vignaud (1997) also noticed differences in the dentition (tooth count and crown shape proportions) between 'Steneosaurus' leedsi Andrews, 1909, and 'S.' megarhinus.

Pierce et al. (2009) hypothesised that 'Steneosaurus' megarhinus was a synonym of 'Steneosaurus' leedsi. Under the rules of the ICZN Code this would have resulted in 'S.' megarhinus being the senior subjective synonym, not 'S.' leedsi (contra Pierce et al., 2009 who considered 'S.' leedsi as the senior synonym). It would also indicate a species that lasted for approximately 12 million years, and was morphologically distinct at both chronostratigraphic termini. However, the teleosauroid species diagnoses of Pierce et al. (2009) have been criticised as being diagnostic only to the generic level or using characters that describe all teleosauroids (Martin \& Vincent 2013, p. 194). Furthermore, Pierce et al. (2009) reported that S. megarhinus is known "from the Oxfordian-Kimmeridgian of England and Germany" (sic). However, contra Pierce et al. (2009, p. 1067), we cannot find any mention of any German or Oxfordian specimens referred to 'S.' megarhinus, by Vignaud (1995) or anyone else.

The validity problem of ' $S$.' megarhinus is due to the use of overall upper jaw tooth total count as the sole means to differentiate the taxon from other teleosauroids (e.g. Vignaud et al. 1993; Pierce et al. 2009). This has caused considerable confusion on the taxonomy of long snouted teleosauroids. Thus, it is not surprising that the validity of the species has been questioned. Instead, other significant features (e.g. the characteristic shape and extreme lateral expansion of the premaxilla, the arrangement of the premaxillary alveoli, and number of 
109 premaxillary alveoli) are rarely (if ever) considered in systematic studies of teleosauroids, until

110 this study.

111 Only one phylogenetic analysis (Mueller-Töwe 2006), so far, has included 'S.'

112 megarhinus and recovered 'S.' megarhinus as the sister taxon to Teleosaurus cadomensis

113 Lamouroux, 1820 (the type species of Teleosaurus), based on prefrontal characters (Mueller-

114 Töwe 2006). This would be consistent with the placement of 'S.' megarhinus as a species of

115 Teleosaurus, as originally proposed by Hulke. Subsequently, the validity and systematics of

116 'Teleosaurus' megarhinus have not been further investigated.

117 Anatomical abbreviations - bo, basioccipital; Dn, $\mathrm{n}^{\text {th }}$ dentary alveolus; $\mathbf{d}$, dentary; en, external

118 nares; exo, exoccipital; fr, frontal; ?j, ?jugal; ?lac, lacrimal; Mn, $\mathrm{n}^{\text {th }}$ maxillary alveolus; ms,

119 mandibular spatula; mx, maxilla; na, nasal; otf, orbitotemproal foramen; oc, occipital condyle;

120 or, orbit; par, parietal; po, postorbital; pop, paraoccipital process; $\mathbf{P n}, \mathrm{n}^{\text {th }}$ premaxillary alveolus;

121 pmx p., premaxillary projection; pmx, premaxilla; ?prf, ?prefrotnal; pro, prootic; pt, pterygoid;

122 q, quadrate; so, supraoccipital; sp, splenial; sq, squamosal; stf, supratemporal fossa; XII, cranial

123 nerve twelve.

124 Institutional abbreviations - BHN, Musée-sur-Mer, Boulogne, France (closed over a decade 125 ago); BRSMG, Bristol Museum and Art Gallery, Bristol, England, UK; CAMSM, Sedgwick

126 Museum, Cambridge, England, UK; DORCM, Dorset County Museum, Dorchester, England,

127 UK; IVPP, Institute of Vertebrate Paleontology and Paleoanthropology, Beijing, China; LPP,

128 Institut de paléoprimatologie, paléontologie, humaine évolution et paléoenvironnements

129 Université de Poitiers, Poitiers, France; MJML, Museum of Jurassic Marine Life - the Steve

130 Etches Collection, Kimmeridge, England, UK; MNHN, Muséum national d'Histoire naturelle, 
131 Paris, France; MNHNL, Muséum national d'Histoire naturelle Luxembourg, Luxembourg City,

132 Luxembourg; NHMUK PV, vertebrate palaeontology collection of the Natural History Museum,

133 London, UK (OR, old register; R, reptiles); NHMW, Naturhistorisches Museum Wien, Vienna,

134 Austria; OUMNH, Oxford University Museum of Natural History, Oxford, England, UK;

135 SMNS, Staatliches Museum für Naturkunde, Stuttgart, Baden-Württemberg, Germany.

GEOLOGICAL SETTING AND PALEOENVIRONMENT

Both NHMUK PV OR 43086 and DORCM G.05067i-v were found at the same general locality:

Kimmeridge Bay (Dorset, UK), the type locality of the Kimmeridge Clay Formation (Fig. 1)

(KCF; Kimmeridgian-Tithonian, 157-148 Ma). In England, the KCF outcrops onshore from

Dorset to Yorkshire, and continues offshore as one of the main source rocks for the North Sea oil industry. Other important KCF localities in the UK are found in Scotland on the western shores of the Isle of Skye (Inner Hebrides) and southern Sutherland (McArthur et al. 2013). The KCF comprises a succession of silicoclastic marine deposits dominated by calcareous organic-rich mudstones, claystones, and siltstones, frequently intercalated with oil-rich shales, and concretionary horizons (Cox and Gallois 1981; Gallois 2004). The KCF is traditionally subdivided into the Lower KCF (Pictonia baylei to Aulacostephanus autissiodorensis ammonite zones - Kimmeridgian) and Upper KCF (Pectinates elegans to Virgatopavlovia fittoni ammonite zones - early Tithonian). The KCF is part of the Ancholme Group that, spanning the MiddleLate Jurassic, offers a relatively continuous lithostratigraphic and fossil record of an epicontinental sea (Jurassic Sub-Boreal Seaway) that covered a large part of the modern British Isles at that time. The KCF strata record a long-term transgressive cycle that started in the middle

153 Oxfordian following a regression phase in the Callovian-early Oxfordian (Coe 1992; Coe 1995; 
154 Cox 2001; Gallois 2004; Weedon et al 2004). The Kimmeridgian strata of the KCF record a

155 deepening phase of the Jurassic Sub-Boreal Seaway, during a period of high global sea levels

156 (Cox 2001). The KCF strata at Kimmeridge Bay span the middle part of the Kimmeridgian stage

157 (Aulacostephanus eudoxus to Pectinatites wheatleyensis ammonite Subzones). Thus, this section

158 likely represents the deepest environment (outer-shelf water depth of 150-200 m) (Gallois 2004)

159 where teleosauroid fossils have been found (see Discussion).

160 The Upper Kimmeridgian strata of the Franculès (Quercy) area where the LPP specimen

161 was found consist of argillaceous limestones intercalated with marls (Fig. 1). The rich ammonite

162 fauna of the section indicates that the teleosauroid fossil come from the $A$. eudoxus ammonite

163 Zone (specifically between the Quercynum Horizon [Caletenum Subzone] and the Contejeani

164 Horizon [Contejeani Subzone]) (Hantzpergue and Lafaurie 1983; Hantzpergue 1989). The

165 associated invertebrate fauna (an ostreid bivalve and ammonite assemblage) indicate a

166 palaeoenvironment no deeper than $100 \mathrm{~m}$ (Hantzpergue and Lafaurie 1983; Hantzpergue 1989).

SYSTEMATIC PALAEONTOLOGY

169

CROCODYLOMORPHA Hay, 1930 (sensu Nesbitt, 2011)

170

THALATTOSUCHIA Fraas, 1901 (sensu Young and Andrade, 2009)

171

TELEOSAUROIDEA Geoffroy Saint-Hilaire, 1831 (sensu Young and Andrade, 2009)

172 BATHYSUCHUS, gen. nov. (Figs 2-8) 
174 ZooBank Life Science Identifier (LSID) for genus: urn:1sid:zoobank.org:act:5D902DD6-AE09-

175 466D-8C40-C729F8481636

176 The electronic version of this article in Portable Document Format (PDF) will represent a

177 published work according to the International Commission on Zoological Nomenclature (ICZN),

178 and hence the new names contained in the electronic version are effectively published under that

179 Code from the electronic edition alone. This published work and the nomenclatural acts it

180 contains have been registered in ZooBank, the online registration system for the ICZN. The

181 ZooBank LSIDs (Life Science Identifiers) can be resolved and the associated information viewed

182 through any standard web browser by appending the LSID to the prefix http://zoobank.org/. The

183 LSID for this publication is: [urn:1sid:zoobank.org:pub:BA30BB3C-9D18-48ED-A79B-

184 AA660450E54B]. The online version of this work is archived and available from the following

185 digital repositories: PeerJ, PubMed Central and CLOCKSS.

186

187 Type Species - Bathysuchus megarhinus gen. et comb. nov. (type by monotypy).

188 Etymology - Meaning deep water crocodile. ' $\beta \alpha \theta v$ c (bathus)' is Ancient Greek for 'deep', and -

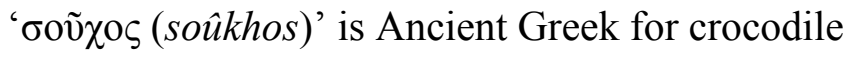

Diagnosis - Same as for the only known species (type by monotypy).

BATHYSUCHUS MEGARHINUS, gen. et comb. nov.

$193 \quad \mathrm{~V}^{*} 1871$

Teleosaurus megarhinus nov. sp.; Hulke, p. 442-443, pl. 18, fig.1-3 
194 v $1872 \quad$ Steneosaurus morinicus (sic) nov. sp.; Sauvage, p. 180

195 v $1874 \quad$ Steneosaurus morinicus Sauvage; Sauvage, p. 38-40

196 v $1888 \quad$ Steneosaurus megarhinus (Hulke, 1871)- Lydekker, p. 117

197 v $1936 \quad$ Steneosaurus megarhinus (Hulke, 1871) - Kuhn, p. 39

198 v $1936 \quad$ Steneosaurus morinicus Sauvage $1874-$ Kuhn, p. 33

199 v 1958 Teleosaurus megarhinus Hulke, $1871-$ Delair, p. 57

200 v $1973 \quad$ Steneosaurus megarhinus (Hulke, 1871) - Steel, p. 33

201 v $1973 \quad$ Steneosaurus morinicus Sauvage 1874 - Steel, p. 32

202 v $1986 \quad$ Steneosaurus morinicus Sauvage 1874 - Buffetaut et al., p. 80-81

203 v $1993 \quad$ Steneosaurus cf. megarhinus (Hulke, 1871) - Vignaud et al., p.1509-1514, fig.2

204 v $2006 \quad$ Steneosaurus megarhinus (Hulke, 1871)-Mueller-Töwe

205 v $2009 \quad$ Steneosaurus leedsi (Andrews, 1909) - Pierce et al.

206 v 2012 Steneosaurus megarhinus (Hulke, 1871) - Bronzati et al.

208 Holotype - The specimen NHMUK PV OR 43086 is an incomplete, diagenetically damaged

209 and partially reconstructed snout (including fragments of the anterior maxillae and posterior

210 processes of the premaxillae) (Fig. 2). Although this specimen is partially distorted, after careful

211 examination of the specimen (as well as more deformed specimens from closely related species) 
212 we consider the deformation on the holotype to be minimal. Crucially the morphology of the

213 premaxillae is considered genuine and is consistent with the other referred - and less distorted -

214 specimens.

215 Referred specimens - DORCM G.05067i-v is an incomplete but well-preserved and minimally

216 distorted snout (i) (Fig. 3), including most of the premaxillae and a limited portion of the anterior

217 parts of the maxillae, which was found at the same locality and in the same horizon as the type

218 species. A complete tooth (v) (Fig. 7) and three well preserved osteoderms (ii-iv) (Fig. 8) were

219 also found associated with the snout.

Another specimen from Francoulès, Quercy area, France (A. eudoxus ammonite Zone)

221

222

223

224

225

226

227

228

229

230

231

232

233

234 was referred to as 'Steneosaurus' cf. megarhinus and is now housed at the Université de Poitiers (LPP) (Figs. 4-6). Vignaud et al. (1993) described this specimen, which consists of: two skull pieces, one being the rostrum and the second the posterior skull (Figs. 4-5); and the anterior portion of the mandibular symphysis, posteriorly broken between alveoli D28 and D29 (Fig. 6). The rostrum is well preserved; however, the skull is broken and displaced and several parts are replaced by plaster. This makes the sutures of the dorsal surface nearly indistinguishable. The orbits appear circular/subcircular in dorsal view (Fig. 5); the anteromedial margins of both orbits have been dorsally displaced across a fracture that has dorsally displaced the entire postorbital skull. Thus, all available information pertaining to the posterior cranium and lower jaw of Bathysuchus comes from this specimen. Vignaud et al. (1993) considered this specimen to be a juvenile based on the smooth ornamentation of the dermatocranium, and the unclosed postfrontal-frontal and nasal-frontal sutures. While we agree that the specimen is probably immature (based on size comparisons with other referred taxa), we also argue that the abovementioned features cannot be convincingly used to support this conclusion (see Discussion). 
235 Other material - Vignaud (1995) also referred an anterior fragment of the mandible (BHN 2R

236 25; the holotype of 'Steneosaurus' morinicus Sauvage, 1872) as 'T'. megarhinus. We have not

237 seen this specimen (composed of the anterior mandibular symphysis and two associated

238 vertebrae) and, based on information in the literature, we cannot confidently comment on its

239 affinities.

240 Type horizon-A. autissiodorensis ammonite Zone, Kimmeridge Clay Formation.

241 Diagnosis - Longirostine teleosauroid (rostrum 71\% of total basicranial length)

242 crocodylomorph with the following unique combination of characters among thalattosuchians

243 (autapomorphic characters are indicated by an asterisk*): the premaxillae have five alveoli

244 (shared with Platysuchus multiscrobiculatus Berckhemer, 1929, Teleosaurus cadomensis

245 Lamouroux, 1820; 'Steneosaurus' jugleri nomen dubium (V. Meyer, 1845); 'Steneosaurus'

246 deslongchampsianus (Lennier, 1887, Savalle 1876)); the P1 and P2 alveoli are lateral to each

247 other at the anterior margin of the premaxilla (shared with Mycterosuchus nasutus Andrews,

248 1913; 'Steneosaurus' jugleri, and probably Aeolodon priscus); in dorsal view the external nares

249 have an ' 8 ' shape, created by one enlarged anteriorly-directed and one dorsally-directed

250 projections of the of the premaxilla (shared with Mycterosuchus nasutus; and possibly

251 'Steneosaurus' jugleri, Teleosaurus cadomensis (see Eudes-Deslongchamps, 1870; Brignon,

252 2014) and 'Steneosaurus' megistorhynchus Geoffroy, 1831 (emend. Eudes-Deslongchamps,

253 1866)); the external nares are antero-dorsally oriented (shared with 'Steneosaurus' brevior Tate

254 and Blake, 1876, Mycterosuchus nasutus, Platysuchus multiscrobiculatus and the Chinese

255 teleosauroid (IVPP V 10098, previously referred to as Peipehsuchus [see Li 1993]); reduced

256 anteroposterior length of the external nares: more than $67 \%$ of the premaxillae total length is

257 posterior to the external nares [shared with 'Steneosaurus' gracilirostris Westphal, 1961 and the 
258 Chinese teleosauroid (IVPP V 10098), 'Steneosaurus' brevior, and Lemmysuchus obtusidens

259 (Johnson et al. 2017); considerably pronounced lateral expansion of the premaxilla*; the anterior

260 and anterolateral margins of the premaxillae are strongly anteroventrally deflected and extend

261 ventrally (shared with 'Steneosaurus' brevior, Mycterosuchus nasutus, Platysuchus

262 multiscrobiculatus and the Chinese teleosauroid) [note that the extent of the premaxillary

263 deflection could be hidden in dorsoventrally compressed specimens. In order to avoid

264 overinterpretations, in this study we exclusively discussed (and scored) this character in first-

265 hand examined, or obviously well-preserved specimens]; inconspicuously ornamented maxillary

266 dorsal surface (shared with the Chinese teleosauroid, and Aeolodon priscus), consisting of a

267 shallow irregular pattern of ridges and anastomosing grooves; nasal, prefrontal, lacrimal are also

268 inconspicuously ornamented; absent/extremely reduced frontal ornamentation (shared with

269 Aeolodon priscus); the rostrum narrows markedly immediately anterior to the orbits (shared with

270 Teleosaurus cadomensis and Mycterosuchus nasutus); in dorsal view, the minimum interorbital

271 width across the frontal is broader than the orbital width (shared with 'Steneosaurus' bollensis

272 von Jäger, 1828, Platysuchus multiscrobiculatus, Teleosaurus cadomensis, 'Steneosaurus'

273 brevior, and 'Steneosaurus' gracilirostris); small and reduced occipital tuberosities; anterior

274 maxillary interalveolar spacing is sub-equal to longer than adjacent alveoli; lack of apical tooth

275 ornamentation*; in the mandible, the fifth dentary alveolar pair is posterolaterally oriented and

276 on the posterior end of the mandibular spatula (rather than posterior to the mandibular spatula)*;

277 the ornamental pits on the dorsal osteoderms are circular and regularly organised in alternate

278 rows (shared with Aeolodon priscus).

279 Remarks. The LPP specimen has a basicranial length of approximately $78 \mathrm{~cm}$, which using the

280 body length equations of Young et al. (2016) yields a $4 \mathrm{~m}$ total body length estimate. Based on 
281 the skull proportions of the most complete specimen (the LPP specimen), the holotype

282 Bathysuchus megarhinus individual (NHMUK PV OR 43086) would have had a basicranial

283 length of approximately $85 \mathrm{~cm}$, and using the body length equations of Young et al. (2016) is

284 estimated at $435 \mathrm{~cm}$ in body length. Comparing overlapping elements amongst the available

285 specimens, we notice that the DORCM specimen was undoubtedly larger than the holotype, but

286 unfortunately its size cannot be confidently estimated.

287 Geographical and Stratigraphic Range. Kimmeridgian of England (A. autissiodorensis

288 ammonite Zone) and France (A. eudoxus ammonite Zone)

\section{DESCRIPTION}

291

292

293

294

295

296

297

298

299

300

301

302

303

\section{Cranial elements}

Premaxillae. The premaxillae of Bathysuchus megarhinus are ladle-shaped elements with a strongly convex dorsal side and strongly concave ventral surface (Figs. 2-4). The premaxillae of the holotype (NHMUK PV OR 43086) each bear five alveoli (although the last one is difficult to see in ventral view due to poor preservation). Unfortunately, the P5 alveoli cannot be seen in DORCM G.05067i due to the poor preservation of both the premaxilla posterior to the P4 alveoli and the premaxilla-maxilla suture (Fig. 3). Such a high alveolar count is unusual amongst teleosauroids, being known only in B. megarhinus and P. multiscrobiculatus (MNHNL TU895, SMNS 9930), as well as having been reported in T. cadomensis (see Lamouroux, 1820; Eudes-Deslongchamps 1869; Westphal, 1961, 1962; Johnson et al., 2018), 'Steneosaurus' deslongchampsianus (Lennier, 1887) (Godefroit et al. 1995) new specimens referred to 'Steneosaurus' jugleri (V. Meyer, 1845) (Schaefer et al. 2018), but not Aeolodon priscus (contra Godefroit et al. 1995). The distribution of the premaxillary alveoli differs in 
304 teleosauroids and has phylogenetic importance. In Bathysuchus, Aeolodon (MNHN.F.CNJ 78),

305 Mycterosuchus (CAMSM J.1420), and 'Steneosaurus'jugleri (SCR011-406), in fact, the P1 and

306 P2 alveoli are regularly circular/subcircular and laterally aligned. This differs in 'Steneosaurus'

307 leedsi, 'S.' heberti, and Machimosaurini, where P2 is posterior and lateral compared to P1,

308 giving the anterior premaxilla a tapering shape. In these taxa, the P1 and P2 alveoli are very

309 close together, have an irregular (oval/teardrop shape) and in Lemmysuchus obtusidens they are

310 separated by only a thin lamina (Johnson et al. 2017). In Bathysuchus, [and to a minor extent in

311 Aeolodon (MNHN.F.CNJ 78), Mycterosuchus (NHMUK PV R 2617, CAMSM J.1420) and

312 'Steneosaurus' jugleri (SCR011-406)], the lateral margins of the premaxillae are strongly

313 laterally expanded, so that the P3-P4 alveoli are anteroposteriorly aligned on a more lateral plane

314 than the external margin of the P2 alveoli. Posterolateral to the P2 alveolus is a noticeable

315 diastema (separating it from the P3 alveolus). The P3 and P4 alveoli are also well separated, and

316 the P5 alveolus is small, positioned dorsally compared to P1-4 and laterally and posteriorly

317 oriented. This morphology is unique in Bathysuchus megarhinus and is clearly visible on

318 NHMUK PV OR 43086 and the LPP (Quercy) specimen (Figs. 2-4, 9).

319 The external nares are well preserved in both NHMUK PV OR 43086 and DORCM

320 G.05067i, but less so in the LPP specimen, where only the anterior portion is partially exposed

321 from the matrix that fills the narial cavity. The anteromedial and posteromedial margins of the

322 external nares are exceptionally bulbous, and project anteriorly and dorsally, respectively (Hulke,

323 1871) (Figs. 2F, 2L, 3E, 3J, 9). This gives the external nares a peculiar '8-shape' in dorsal and

324 anterior views (Figs. 2F, 2L, 3E, 3J, 9), which is not evident in any other teleosauroid besides

325 Mycterosuchus nasutus (CAMSM J.1420, DF, pers. obs.). However, this area is too damaged

326 in Aeolodon (MNHN.F.CNJ 78) to be confidently assessed (Figs 9D-E, 10). Overall, the external 
327 nares constitute a small length of the entire premaxillae; the portion of the premaxilla posterior to

328 the external nares is more than $67 \%$ of its entire length, longer than in A. priscus (MNHN.F.CNJ

329 78), where it is approximately $60-65 \%$ (it is between $50-65 \%$ in the basal 'S.' gracilirostris and

330 'S.' leedsi). The anterior and posterior medial margins of the external nares are made by two

331 bulbous projections of the premaxillae in the dorsal and anterior directions, respectively (Hulke

332 1871) (Figs. 2F, 2L, 3E, 3J, 9D-F). Faint, weak ridges ornament the anterior margin of the

333 anterior projection and the external nares of B. megarhinus (NHMUK PV OR 43086, DORCM

334 G.050671i); these ridges are commonly present in other teleosauroids (e.g. Lemmysuchus

335 obtusidens NHMUK PV R 3168).

336 The premaxillae in both Dorset specimens (NHMUK PV OR 43086 and DORCM

337 G.05067i) are laterally expanded (such that they extend considerably more laterally than the

338 anterior maxilla lateral margins) in line with the P3-P4 alveoli, and are also strongly ventrally

339 deflected (Figs. 2-4, 9F). The lateral expansion of the premaxillae cause P3-P4 to be positioned

340 on a plane lateral to the rest of the premaxillary and maxillary alveoli. Due to the ventral

341 deflection, the P1-P3 alveolar margin is also situated on a ventral plane compared to the

342 remaining snout dentition, including the $\mathrm{P} 4$ alveoli (which is more dorsally and slightly

343 posteriorly oriented) (Figs. 2C, 2I, 3C, 3H, 4C, 4G, 9). The lateral premaxillary expansion is not

344 uncommon in teleosauroids within the subclade including 'Steneosaurus' brevior and

345 Mycterosuchus nasutus-(Fig. 9). Yet, it is noticeably more extreme in Bathysuchus megarhinus

346 than in the other taxa. It is possible that this condition has been slightly exaggerated by the

347 preservation of the specimens. However, we see no reason why a dorsoventral compaction would

348 result in moving the premaxillae downwards rather than buckling it on the same level as the

349 maxillae (as it can be seen in Mycterosuchus nasutus, 'Steneosaurus' leedsi and other 
350 dorsoventrally flattened specimens of the Oxford Clay Formation) (Fig. 9). Notably the

351 difference between the latter two taxa is still visible regardless of diagenetic flattening. Perhaps

352 more convincingly, NHMUK PV OR 43086 and DORCM G.05067i are not significantly

353 dorsoventrally distorted, as can be assessed by the well-preserved oval shape of their rostrum

354 cross-section (Figs. 2-3). Finally, this set of features (that also affect the orientation and shape of

355 the external nares) is present in the well preserved and undistorted LPP specimen, which is the

356 strongest evidence that they are genuine (Fig. 4).

357 As reported by Hulke (1871), the P4 alveoli are the largest alveoli in the premaxillae, and

358 the P1 and P5 alveoli are the smallest (Figs. 2 -4). In dorsal view, the premaxillae contact the

359 maxillae via a slightly interdigitating, 'V-shaped' suture that reaches level to the M3 alveoli, or

360 slightly posterior. In ventral view, the same suture has a straight anterior margin, creating a sub-

361 square profile with the anterior-most side reaching in between the P3 and P4 alveoli (Figs. 2C,

362 2I, 3C, 3H, 4C, 4G). The ornamentation of the dorsal surface of the premaxillae is weak and

363 shallow, as in $A$. priscus (MNHN.F.CNJ 78), and considerably less pronounced than in $M$.

364 nasutus (NHMUK PV R 3577, and CAMSM J.1420), 'S.' brevior (NHMUK PV OR 14781) and

365 taxa within Machimosaurini (e.g. Lemmysuchus obtusidens NHMUK PV R 3168;

366 Machimosaurus buffetauti V1600Bo) (Figs. 2-4, 11).

As well as NHMUK PV OR 43086 and DORCM G.05067i, the LPP specimen shows the

combination of characteristic premaxillary and maxillary features of Bathysuchus: (1) five

premaxillary alveoli (with the P5 being small and posteriorly oriented); (2) extreme lateral

370 expansion of the premaxillae; (3) the premaxilla posterior to the external nares is over $67 \%$ of its

371 entire length; (4) the P1 and P2 alveoli are laterally aligned and do not form a couplet; (5) the

372 P3-P4 alveoli are anteroposteriorly aligned more laterally than the P1-P2; (6) P1-P3 alveoli are 
373 situated on a ventral plane compared to the rest of the premaxillary alveoli; (7) faint, shallow

374 ornamentation on the premaxillae. As the interpremaxillary septum is slightly broken/covered by

375 matrix in the LPP specimen, we cannot assess whether the external nares were '8-shaped' with

376 bulbous anteromedial and posteromedial margins. They were, nevertheless, anterior-dorsally

377 oriented and shorter than their width.

378 Maxillae. The maxillae are partially preserved in both NHMUK PV OR 43086 and

379 DORCM G.05067i (although they are slightly more complete in NHMUK PV OR 43086), but

380 their sutures with adjacent posterior elements cannot be assessed (Figs. 2-4) (however they are

381 more completely preserved in the LPP specimen, see below). The maxillae form a substantial

382 part of the rostrum, with sub-parallel lateral margins in dorsal view. The rostrum is

383 dorsoventrally flattened (oval in cross section with a horizontal long axis) (Fig. 2E, 2K). The

384 dorsal and lateral surfaces of NHMUK PV OR 43086 and DORCM G.05067i are weakly

385 ornamented with a shallow network of ridges, rugosities and anastomosing grooves (Figs. 2-3,

386 11). The density and depth of the maxilla ornamentation varies in teleosauroids, and in semi-

387 aquatic taxa the loss of dermatocranial and osteoderm ornamentation has been linked to a pelagic

388 lifestyle (Young et al. 2013; Clarac et al. 2017) (see Discussion). This is similar to the

389 evolutionary trend in metriorhynchids, which plesiomorphically had well ornamented

390 dermatocrania that independently became 'smoother' in numerous lineages through time (Young

391 et al. 2013).

With reference to the LPP specimen (Figs. 4-5) (also see Fig. 2 Vignaud et al. 1993, and

Plate 12, Vignaud 1995), the rostrum of B. megarhinus makes up approximately $71 \%$ of the total 
396 length in teleosauroids ranges from 55-75\%, with Machimosaurus mosae Sauvage \& Liénard,

3971879 having the lowest rostrum/basicranial length ratio in teleosaurids and ' $S$.' leedsi $(\sim 72 \%), M$.

398 nasutus, 'Steneosaurus' deslongchampsianus, and A. priscus the highest ( $74 \%)$. This suggests

399 that rostrum length is a plastic feature in teleosauroids, with different clades independently

400 diverging from the plesiomorphic longirostry towards extreme longirostrine or

401 mesorostrine/brevirostrine forms.

402 Given the incomplete preservation of these specimens, it is impossible to provide a

403 precise tooth count for B. megarhinus. The Quercy referred specimen (Vignaud et al. 1993;

404 Vignaud 1995) has 28-30 preserved maxillary alveoli, but the tooth row is posteriorly

405 incomplete. Approximately 24 anterior-most alveoli are preserved on each side of NHMUK PV

406 OR 43086, and only the three anterior-most alveoli are preserved on the right maxilla of

407 DORCM G.05067i. The maxillary interalveolar spacing is regular and in the anterior third of the

408 maxilla, it is longer than the adjacent alveolar length (Figs. 2-4). The palatines are not visible in

409 any of the Dorset specimens. Vignaud et al. (1993) reported that in the LPP specimen the

410 palatines occupy the entire width of the beginning of the rostrum (in line with the anterior margin

411 of the orbits), and the maxillae are reduced to thin lateral bands. It is not possible to accurately

412 estimate the anterior extent of the palatine-maxillae suture in relation to the tooth count, but it

413 certainly does not extend more than approximately $\sim 5 \mathrm{~cm}$ anterior to the posterior end of the

414 rostrum, roughly corresponding to the position of the M27-M30 alveoli (also see Fig. 2 Vignaud

415 et al. 1993; Plate 12, Vignaud 1995).

416 The maxillae of the LPP specimen are anteroposteriorly elongated with sub-parallel

417 lateral margins as in other teleosauroids (e.g. Lemmysuchus obtusidens NHMUK PV R 3168). In

418 dorsal view, the rostrum narrows markedly immediately anterior to the orbits, which is also seen 
419

420

421 422 tooth row.

423

424

425

426

427

428

429

430

431

432

433

434

435

436

437

438

439

440

441

in T. cadomensis (MNHN.F AC 8746), A. priscus (MNHN.F.CNJ 78) and M. nasutus (NHMUK

PV R 3577). The LPP specimen has approximately 28-30 preserved maxillary alveoli, although

the posterior-most alveoli are not preserved, and M30 does not correspond with the end of the

Nasals, frontal and postorbital. The nasals are elongated and triangularly shaped as in other thalattosuchians (Andrews 1913; Young et al. 2014) and do not contact the premaxilla, although it is impossible to precisely determine their anterior extent. Based on the break of the rostrum (M25-M26) and the posterior skull, it can be estimated to be around the M27-M30 interval. The frontal (although the anterior part is severely distorted) is a large, single bone that is similar in shape to that in most other teleosauroids (e.g. 'S.' leedsi NHMUK PV R 3806; see Andrews 1909, 1913). The minimum interorbital width across the frontal is broader than the orbital width, shared with 'S.' bollensis (SMNS 51753), P. multiscrobiculatus (SMNS 9930), $T$. cadomensis (MNHN.F AC 8746), 'S.' brevior (NHMUK PV OR 14781) and 'S.' gracilirostris (NHMUK PV OR 14792). One peculiar feature is the absent/faint ornamentation on the frontal, which is also seen in Aeolodon priscus (note that Vignaud et al. (1993) suggested that this feature could be a juvenile characteristic) (see Discussion) (Figs. 5, 10). Only the right postorbital is near-completely preserved (Fig. 5). However, the posterior end is broken and slightly anteroventrally displaced. The postorbital forms the lateral and posteroventral borders of the supratemporal fenestra. The frontal and postorbital form the postorbital bar (although the contact between the two bones cannot be seen clearly), which is mediolaterally short and slightly anteroposteriorly slender.

Postorbital cranium. The parietal is large, fused and unornamented (Fig. 5). The supratemporal fenestrae are large, anteroposteriorly elongated and sub-rectangular in shape (in 
442 dorsal view), similar to those seen in most teleosauroids [e.g. 'S.' leedsi (NHMUK PV R 3806), 443 A. priscus (MNHN.F.CNJ 78), M. nasutus (NHMUK PV R 3577) and S. bollensis (e.g. SMNS

444 51753)]. Their lateral margins appear relatively straight in dorsal view (Fig. 5A, 5F) and concave 445 in lateral view (although the right supratemporal fenestra is diagenetically disfigured in lateral 446 view) (Fig. 5B, 5G, 5D, 5I). The squamosals (Fig. 5) are damaged, especially in the anterior area. 447 However, they appear to be L-shaped, as in other teleosauroids (e.g. 'S.' leedsi NHMUK PV R 448 3806). The squamosal forms the posterolateral border of the supratemporal fenestra. Occiput. In occipital view (Fig. 5E, 5J), the supraoccipital is dorsoventrally tall. The

450 exoccipitals (which make up the majority of the occiput) are large, tilted dorsally and slightly concave and flared dorsoventrally. The cranial nerve XII foramen is level with the foramen magnum, and the quadrates appear relatively small, each bearing two separate hemicondyles. The occipital tuberosities are small and reduced as in other teleosauroids such as 'S.' leedsi (NHMUK PV R 3806) (one exception is 'Steneosaurus' heberti Morel de Glasville, 1876 (MNHN.F 1890-13), in which they are large and bulbous). The exoccipitals meet at the midline and are dorsoventrally broad, relatively anteroposteriorly short and extend horizontally (Fig. 5E, 5J). The paraoccipital process is the same size as the remainder of the exoccipital. In the LPP specimen, the left exoccipital is ventrally displaced.

Mandible. The LPP mandible is preserved up to the D28 alveolar pair (Fig. 6). The spatulate anterior area is broken and its anterior part has been dorsally displaced. The anterior spatula is similar in shape and proportion to that of other longirostrine teleosaurids: D1-D2 are widely separated by a noticeable notch (presumably for the P3 tooth) from D3-D4. D4 and D5 are also separated by a diastema. However, uniquely in Bathysuchus megarhinus, the D4-D5 interalveolar space is reduced and D5 sits on the posterior end of the "spatula". Consequently, 
465 D5 is on the same lateral plane as D2-3-4 rather than being in line with the other dentary teeth of

466 the symphyseal area. Posterior to the spatulate area, the dentary interalveolar spacing is

467 consistently sub-equal to one alveolar length (and slightly increases along the tooth row in

468 posterior direction) (Fig. 6).

469 Dentition. No teeth are preserved in the type specimen, with DORCM G.05067v having 470 one loose tooth crown that is well preserved enough to allow description (Fig. 7). The crown is 471 small, only $\sim 17 \mathrm{~mm}$ in apicobasal length, with a high crown base average diameter/ crown height

472 ratio $(\sim 2.5)$. The crown is sub-circular in cross section at its base, slightly laterally compressed in 473 the apical third, and it is weakly curved in medial direction. The enamel is finely ornamented by 474 continuous parallel apicobasally aligned ridges that are densely packed and low-relief. The 475 ridges do not reach the apex of the tooth, but stop two-thirds up the crowns in both the mature 476 and unerupted teeth (left P4 and M2). DORCM G.05067v has one visible carina on both mesial 477 and distal margins. The carinae are easier to detect on the apical third of the crown, and they are 478 smooth, as no denticles can be observed (even using optical aids). Following the functional 479 classification of Mesozoic marine reptile teeth by Foffa et al. (2018), B. megarhinus (DORCM 480 G.050761v) falls in the 'Pierce' guild, along with the other non-Machimosaurini teleosauroids in 481 the dataset.

482 There is one tooth (P4) preserved in situ in the LPP skull, and three more in the mandible 483 (D15 on the right side, D18 and D20 on the left side) (Fig. 6). The teeth are slender, sub-circular 484 in cross section, apicobasally elongated and weakly curved in the lingual direction.

485 Unfortunately, they are all incomplete and partially covered with matrix, hiding their apices and 486 enamel ornamentation. 
Osteoderms. No osteoderm was found associated with the holotype or LPP specimen,

488

489

490

491

492

493

494

495

496

497

498

499

500

501

502

503

504

505

506

507

508 but three osteoderms (two dorsal-sacral and one ventral) are preserved in DORCM G.05067i-iv

(Fig. 8). Based on their respective rectangular and sub-circular shapes, the dorsal osteoderms

presumably come from one of the paramedian series of the dorsal series (DORCM G.05067ii)

(Fig. 8A-B) and the anterior tail (DORCM G.05067iv) (Fig. 8C-D). All osteoderms are relatively

reduced in size and thickness compared to all other teleosaurids except Aeolodon priscus They

are ornamented with small circular/sub-circular pits that are organised in alternate rows, unlike in

the usual 'starburst' patterns of tear-drop/irregular shaped pits of most teleosauroids [e.g.

machimosaurins; see Young et al. (2014), Johnson et al. (2017)]. The regular shape and

arrangement of these pits is similar to the morphology observed in A. priscus (MNHN.F.CNJ 78)

(Fig. 10) and 'Steneosaurus' jugleri (Godefroit et al. 1995). The caudal osteoderm, DORCM

G.05067iv, has a well-developed medial keel that is not present in the other two osteoderms

(although the keel may be missing due to preservation) (Fig. 8A, 8C). The third osteoderm,

DORCM G.05067iii, differs somewhat from the others due to the ornamental pits being more

widely separated from one another, with a flat external surface (Fig. 8E-F). Overall, the

osteoderms of B. megarhinus are poorly ornamented compared to other teleosauroids (e.g. see

Andrews, 1913; Johnson et al., 2017), a character shared with A. priscus (MNHN.F.CNJ 78)

(Figs. 8, 10B, 10C, 11H), and 'Steneosaurus' jugleri (SCR010-312) (Godefroit et al. 1995).

Finally, an osteoderm NHMUK PV OR 40105 of similar shape, preservation and

ornamentation to DORCM G.05067ii was found associated with the matrix of Plesiosuchus

manselii (NHMUK PV OR 40103), which was from the A. autissodorensins Sub-Boreal

ammonite Zone (Lower Kimmeridge Clay Formation of Kimmeridge Bay) - the same locality of 
509 the UK specimens of Bathysuchus megarhinus. However, given its poor preservation, we cannot

510 be certain it belongs to Bathysuchus megarhinus.

\section{PHYLOGENETIC ANALYSIS}

\section{Methods}

513 We conducted a phylogenetic analysis to test the evolutionary relationships of Bathysuchus

514 megarhinus gen. nov. within Thalattosuchia, using a modified version of the dataset published by

515 Ösi et al. (2018), which is continuously being updated, as it forms the foundation of the ongoing

516 Crocodylomorph SuperMatrix Project. The dataset was first presented in Ristevski et al. (2018);

517 however, it has been extensively updated subsequently (see Ösi et al. (2018) for full details). All

518 data are summarised in Supplementary data files.

519 The current dataset consists of 140 crocodylomorph OTUs (70 of which are

520 thalattosuchians, including 18 teleosauroids, seven basal metriorhynchoids and 42

521 metriorhynchids) scored for 456 characters. Of these 456 characters, 25 characters representing 522 morphoclines were treated as ordered (see DatasetS1) and Postosuchus kirkpatricki Chatterjee,

5231985 was used as the outgroup taxon. The differences between our analyses and those presented

524 by Ösi et al. (2018) are: (1) the rescoring of B. megarhinus, M. nasutus and A. priscus; (2) the

525 rescoring of the Chinese teleosauroid (IVPP V 10098) OTU; and (3) a re-organisation of the

526 character list, with the addition of 3 new characters (Ch. 31, 274, 275), deletion of one (former

527 Ch. 42), and inclusion of two new anatomical sections (palaeoneuroanatomy and

528 craniomandibular pneumaticity). The character scoring for B. megarhinus was based on first-

529 hand examination of the holotype by DF, MMJ and MTY, as well as first-hand examination of

530 the referred DORCM specimen Bathysuchus by DF and the LPP specimen by MMJ. Due to the 
531 poor preservation and incompleteness of these specimens, B. megarhinus was scored for 159 out 532 of 456 characters $(35.0 \%)$.

533 The protocol used to analyse the dataset is the same adopted by Ösi et al. (2018), and it is 534 described in detail in DatasetS1.

535

536 Results

537 The phylogenetic analysis produced 85 most parsimonious trees (MPTs) with 1494 steps

538 (ensemble consistency index $(\mathrm{CI})=0.414$; ensemble retention index $(\mathrm{RI})=0.841$; rescaled

539 consistency index $(\mathrm{RCI})=0.348$; ensemble homoplasy index $(\mathrm{HI})=0.586)($ Fig. 12$)$. The overall

540 strict consensus topology recovered from this analysis is little different from those presented by

541 Ristevski et al. (2018) and Ösi et al. (2018).

542 The overall picture of crocodylomorph interrelationships are similar to those found in

543 previous iterations of this merged dataset (Ristevski et al., 2018; Ösi et al., 2018). Thalattosuchia

544 is monophyletic within Crocodyliformes but outside Metasuchia. Within Thalattosuchia, both

545 Teleosauroidea and Metriorhynchoidea are recovered as monophyletic, with Eopneumatosuchus

546 colberti Crompton \& Smith, 1980 from the Kayenta Formation of Arizona, USA (Curtis and

547 Padian, 1999) as their closest outgroup. In Metriorhynchoidea, Pelagosaurus typus Bronn, 1841

548 is positioned as a basal metriorhynchoid, and Metriorhynchidae, Metriorhynchinae,

549 Rhacheosaurini, Geosaurinae and Geosaurini are all monophyletic. Within Teleosauroidea,

550 'Steneosaurus gracilirostris' is the basal-most species, and there are two large subclades here

551 identified as 'clade T' (including poorly known genera and species (e.g. Platysuchus,

552 Bathysuchus, Teleosaurus and Mycterosuchus) that are predominately long-snouted) ) and 'clade 
553 S' (including 'S.' leedsi, the durophagous tribe Machimosaurini Machimosaurini and all taxa in

554 between) (Fig. 12).

555 Within 'clade T', Bathysuchus megarhinus is found as sister taxon to Aeolodon priscus in 556 a clade also containing Mycterosuchus nasutus (Fig. 12). This subclade is in turn closely related 557 to Teleosaurus cadomensis, Platysuchus multiscrobiculatus, 'Steneosaurus' brevior and the 558 Chinese teleosauroid (Fig. 12) within 'clade T'.

559 Note that our dataset does not include the recently catalogued new available materials of 560 'Steneosaurus' jugleri from the Late Jurassic of Switzerland (Schaefer et al. 2018). The 561 description of the new material and assessment of the validity of this taxon exceeds the scope of

562 the present manuscript. However, given its relative completeness (associated cranial and

563 postcranial material), and the strong similarities (reduced cranial ornamentation and premaxillary 564 alveolar count and arrangement) that this taxon shares with Bathysuchus, we predict that these 565 specimens are bound to improve our knowledge of the relationships of the T-clade.

\section{DISCUSSION}

\section{Comparisons with other teleosauroids}

569 Bathysuchus megarhinus shares a number of characters with other teleosauroids, most notably

570 with a handful of long-snouted taxa (e.g. Mycterosuchus nasutus and Aeolodon priscus,

571 'Steneosaurus' jugleri). As mentioned in the description, the high premaxillary alveolar count

572 (five) is unusual, and is only seen in B. megarhinus (NHMUK PV OR 43086, DORCM

573 G.05067i, LPP specimen), P. multiscrobiculatus (MNHNL TU895, SMNS 9930 MMJ pers.

574 obs.) and T. cadomensis (see Lamouroux 1820; Westphal 1962); 'Steneosaurus'

575 deslongchampsianus (Godefroit et al. 1995, Savalle 1876) and 'Steneosaurus' jugleri (Schaefer 
576 et al. 2018), but not Aeolodon priscus (contra Godefroit et al. 1995). The peculiar premaxillary

577 alveolar distribution of the P1-P2 and the P3-P4 alveoli are characteristic of both B. megarhinus

578 (NHMUK PV OR 43086, LPP specimen, DORCM G.050671i) and M. nasutus (CAMSM J.1420

579 DF, pers. obs.), which is one of a number of features unique to these taxa (Fig. 9). Well-

580 developed anterior premaxillary projections seen in B. megarhinus (NHMUK PV OR 43086 and

581 DORCM G.050671i - but not in LPP specimen, as its narial cavities are infilled with matrix) are

582 also present in M. nasutus (CAMSM J.1420, DF pers. obs.) (Figs. 2-3). This feature is

583 considerably less clear in other teleosauroids, including closely related taxa such as Aeolodon

584 priscus (MNHN.F.CNJ 78), but also 'Steneosaurus' leedsi (NHMUK PV R 3806) and the

585 Chinese teleosauroid (IVPP V 10098). Bathysuchus megarhinus shares three premaxillary

586 features in with P. multiscrobiculatus (SMNS 9930, MNHNL TU895), 'Steneosaurus' brevior

587 (NHMUK PV OR 14781), Mycterosuchus nasutus (NHMUK PV R 2617; CAMSM J.1420), the

588 Chinese teleosauroid (IVPP V 10098), and 'Steneosaurus' jugleri.

589 (1) The anterolateral margins of the premaxillae are strongly anteroventrally deflected (Figs.

$5902-4,9)$. In other teleosauroids (e.g. 'S.' leedsi NHMUK PV R 3806) the anterior and

591 anterolateral premaxillary margins are either not anteroventrally deflected, or not as strongly;

592 (2) The anterior external nares face anteriorly (or anterodorsally) (Figs. 2-4, 9). In other

593 teleosauroids (e.g. 'S.' leedsi NHMUK PV R 3806) the external nares face mainly dorsally;

594 (3) The premaxilla is laterally expanded, in line with the P3-P4 alveoli.

595 In other teleosauroids (e.g. 'S.' leedsi NHMUK PV R 3806, S. edwardsi NHMUK PV R 3701,

596 Machimosaurini) (Young et al. 2014) the lateral expansion and the ventral deflection are not as

597 clear, although we noticed that this feature may be present in Mycterosuchus nasutus (NHMUK 
598

599

600

601

602

603

604

605

606

607

608

609

610

611

612

613

614

615

616

617

618

619

PV R 3577; CAMSM J.1420), Aeolodon priscus (MNHN.F CNJ 78) and 'Steneosaurus' jugleri

(SCR011-406). Furthermore, in Aeolodon the premaxillae are laterally expanded and may be

ventrally deflected, but both features may be concealed by the diagenetic deformation of the

specimens (Fig. 9). Nevertheless, even allowing for deformation the extent of these features do not reach the extreme morphology present in every B. megarhinus specimen.

The teeth of $B$. megarhinus are unusual, as the enamel ridges do not continue onto the apical region (Fig. 7). This feature has not been observed in any other described teleosauroid, in which the enamel ridges are more densely packed and reach the apex (e.g. M. nasutus NHMUK PV R 3577, CAMSM J.1420; A. priscus MNHN.F CNJ 78; 'S.' bollensis MNHNL TU799) (Andrews 1913). However, it is worth noting that it has been observed in an undescribed MNHN teleosauroid (one tooth in association with a partial skull) and NHMW 1884 (from the 'Lias' of Germany), which is labelled as 'Teleosaurus' (however, this tooth is laterally compressed, with discontinuous ridges that are more prominent than in Bathysuchus) (MMJ pers. obs.). The same feature is also visible in one tooth referred to 'Steneosaurus' jugleri (TCH005-151) that is still wanting description (Schaefer et al. 2018).

\section{Reduced ornamentation and possible pelagic adaptations in Teleosauroidea}

The premaxillary and maxillary dorsal and lateral surfaces of B. megarhinus (NHMUK PV OR 43086, DORCM G.05067i) are particularly weakly ornamented, which is similar to the condition in the Chinese teleosauroid (IVPP V 10098), A. priscus (MNHN.F CNJ 78), and 'Steneosaurus' jugleri (SCR011-406) (Figs. 2-5, 8, 10) (Schaefer et al. 2018). This differs from most other teleosauroids, both closely related taxa and more distant relatives, that retain the plesiomorphic 
620 condition of strongly ornamented rostrum and skull roof (Fig. 11) (e.g. M. nasutus NHMUK PV 621 R 3577, CAMSM J.1420; 'S.' brevior NHMUK PV OR 14781; L. obtusidens NHMUK PV R $6223168)$. G.050671i), A. priscus (MNHN.F.CNJ 78) (Figs. 8, 10, 11), and 'Steneosaurus' jugleri (SCR010-312) (see Schaefer et al. 2018). These pits are large, but few in number and well separated from one another when compared to other teleosauroids (Fig. 11). However, there is 627 one notable difference between the osteoderms of B. megarhinus and A. priscus: the thoracic osteoderms of B. megarhinus are not keeled, whereas longitudinal keels are present on all osteoderms in A. priscus (MNHN.F.CNJ 78), even the cervical ones (Figs. 8, 10). R 3577, CAMSM J.1420) (Fig. 11). The pronounced reduction in dermatocranial and osteoderm ornamentation are characters shared between B. megarhinus and A. priscus, and are unique to these two species within Teleosauroidea (Figs. 8, 10, 11). This contrast is striking considering 635 that the heavily ornamented Mycterosuchus nasutus is sister taxon to Aeolodon + Bathysuchus.

637 ornamentation) is characteristic of the shift from amphibious to pelagic forms in

638 Crocodylomorpha (Clarac et al. 2017). Clarac et al. (2017) outlined a possible mechanism for the 639 increase in bone ornamentation in amphibious pseudosuchians, as a way to increase their basking 640 efficiency. As dermatocranial and osteoderm ornamentation is highly vascularised, the overlying 641 soft tissue can drive heat radiation to the bones. We can therefore hypothesise that there was a 
642 thermoregulatory shift in the lineage from Mycterosuchus nasutus to Aeolodon + Bathysuchus.

643 Between the Callovian taxon M. nasutus, and the late Kimmeridgian-early Tithonian Aeolodon +

644 Bathysuchus subclade there was a reduction in the size and thickness of their osteoderms, as well

645 as a pronounced reduction in their dermatocranial and osteodermal ornamentation. We here

646 hypothesise that this was in response to living in different habitats: heavily ornamented forms in

647 semi-aquatic coastal environments and weakly ornamented forms in a more pelagic habitat, in

648 which basking was less important (or perhaps impossible). A similar reduction in dermatocranial

649 and osteodermal ornamentation is also seen in Metriorhynchidae, which are well established as

650 fully pelagic thalattosuchians (Fraas 1902; Andrews 1913; Fernández and Gasparini

651 2008; Herrera et al. 2013; Herrera et al. 2017).

653 (unfortunately the post-cranium of $B$. megarhinus is largely unknown). The largest $A$. priscus

654 specimen, MNHN.F.CNJ 78, has proportionally very small dorsal osteoderms, proportionally

655 short tibiae, and reduced forelimbs that have become more flipper-like. These reduced limb

656 measurements contrast with almost all other teleosauroids with known postcranial skeletons (Fig.

657 13) (DatasetS2). To quantitatively demonstrate this, we selected two limb measurements to

658 examine. The first is a ratio of the forelimb and hindlimb propodials (humerus : femur or H:F).

659 This was chosen as a proxy for the relative reduction of the forelimb, as few metriorhynchid

660 specimens have associated forelimb stylopodial elements, and even fewer a preserved manus.

661 Within Metriorhynchidae the morphofunctional changes that transformed the forelimb into a

662 hydrofoil-like structure resulted in it being greatly reduced in relative size compared to the

663 hindlimb (e.g. Fraas 1902). Secondly, we used the tibia : femur (T:F) ratio, because within

664 Crocodylomorpha the tibia is proportionally reduced in size relative to the femur in numerous 
665 lagoonal and pelagic taxa (Fraas 1902; Andrews 1913; Wu et al. 2001; Schwarz et al. 2006;

666 Buscalioni et al. 2011. We produced and examined two distinct datasets including

667 thalattosuchians, and extant crocodylomorphs (H:F - 26 teleosauroids; 10 metriorhynchoids; 39

668 extant specimens; and T:F - 31 teleosauroids; 11 metriorhynchoids; 39 extant specimens)

669 (DatasetS2). The measurements of extant specimens were selected from Iijima et al. (2018)

670 dataset, while thalattosuchian measurements were personally taken by DF, MTY or MJ or come

671 from Mueller-Töwe (2006) (DatasetS2).

672

The first intriguing feature is that the H:F and T:F linear equations of teleosauroids,

673 metriorhynchids and extant species noticeably differ. This further highlights that the body-plans

674 of these three groups where distinctly different, as the linear equations of basicranial length-total

675 body length and femoral length-total body length are already known to have noticeably differed

676 between them (see Young et al. 2011, 2016). Overall, relative to extant crocodylians,

677 thalattosuchians had proportionally: longer skulls relative to total body length, shorter femoral

678 lengths relative to total body length, shorter humeral lengths relative to femoral length, and

679 shorter tibial lengths relative to femoral length. This suggests that thalattosuchians had -

680 compared to modern crocodylians - proportionally larger skulls, shorter femora, smaller

681 forelimbs, and shorter tibiae, perhaps in relation to a marine lifestyle. This contention is

682 supported by the fully pelagic metriorhynchids having even shorter humeri and tibiae relative to

683 the femora than teleosauroids (Fig. 13).

684

When we examine the $\mathrm{H}: \mathrm{F}$ ratio, Aeolodon priscus $(\mathrm{H}: \mathrm{F} \sim 0.36)$ falls very close to the

685 range of pelagic metriorhynchids $(\mathrm{H}: \mathrm{F} \sim 0.20-0.34)$, and outside the range of any other known

686 teleosauroids ( $\mathrm{H}: \mathrm{F} \sim 0.38-0.76$ ) (Fig. 13). In comparison, in extant crocodylians the H:F ratio is

687 considerably higher (H:F $\sim 0.76$ - 0.97), as Crocodylus, Alligator, Gavialis, Mecistops, Caiman, 
688 Melanosuchus, Paleosuchus, Osteolaemus, and Tomistoma have humeri and femoral lengths 689 closer to subequal. The Toarcian teleosauroids have a H:F ratio range of $0.43-0.76$, whereas the 690 Callovian species have a range of $0.38-0.52$, suggesting a generalised trend towards shortening 691 the humeri in Teleosauroidea across time (with the Late Jurassic Aeolodon priscus being the 692 most extreme known example of this trend). of pelagic metriorhynchids (H:F $\sim 0.27-0.43$ ) and other known teleosauroids ( $\mathrm{H}: \mathrm{F} \sim 0.41-0.70$ ) 695 (Fig. 13). In comparison, in extant crocodylians the T:F ratio is again higher (T:F $0.67-0.81)$. The Toarcian teleosauroids have a $\mathrm{T}: \mathrm{F}$ ratio range of $\sim 0.48-0.70$, the Callovian species have a

697

698

699

700

701

702

703

704

705

706

707

708

709

710 range of $0.43-0.51$, and the three known Kimmeridgian-early Tithonian specimens complete enough to include in our dataset have a range of $0.40-0.46$. Once again, there is a generalised trend towards shortening the tibia over time in Teleosauroidea.

Interestingly, these temporal trends independently occurred in the two subclades of Teleosauroidea. The basal Toarcian teleosauroid Steneosaurus gracilirostris has high ratios (H:F $=0.685, \mathrm{~T}: \mathrm{F}=0.687)$. In the ' $\mathrm{T}$ '-subclade, the H:F ratio decreases throughout the Jurassic:

Toarcian $0.683-0.761$ (Platysuchus), Callovian $0.506-0.528$ (Mycterosuchus), and Kimmeridgian 0.36 (Aeolodon). In the 'S'-subclade, the H:F ratio similarly decreases: Toarcian $0.436-0.640$ (S. bollensis), and Callovian $0.384-0.479$ (S. leedsi, S. edwardsi and Lemmysuchus). Similarly, for the T:F ratio, the ' $\mathrm{T}$ '-subclade lowers through the Jurassic:

Toarcian $0.610-0.697$ (Platysuchus), Callovian $0.500-0.510$ (Mycterosuchus), and Kimmeridgian $0.397-0.464$ (Aeolodon). This also occurs in the 'S'-subclade: $0.481-0.643$ ( $S$. bollensis), Callovian $0.434-0.511$ (S. leedsi, S. edwardsi and Lemmysuchus), and Kimmeridgian 0.412 (Machimosaurus mosae). 
712 the appendicular skeleton, and their recovery in deeper-water sediments - hint that by the Late

713 Jurassic, some teleosauroids were beginning to evolve a more pelagic lifestyle. All three lines of

714 evidence are present in A. priscus, whereas two of them are clear in B. megarhinus (reduced

715 ornamentation, recovery in deeper-water sediments; the relevant postcranial bones to examine

716 for limb reduction are not preserved in any known specimen). As these two taxa are united in a

717 clade, we hypothesize that this clade represents a lineage of teleosauroids that evolved from

718 nearshore, lagoonal forms and entered deeper waters, modifying their skeletons as they did so.

719 Interestingly, this pattern may be a response to the deepening of waters in the Late

720 Jurassic. Foffa et al. (2018) showed that teleosauroids and other shallow water taxa underwent a

721 morphological and species diversity decline in the Jurassic Sub-Boreal Seaway (JSBS) across the

722 Middle-Late Jurassic boundary, in concert with deepening of local and global sea-levels. In fact,

723 the whole JSBS marine reptile assemblage and ecological niches changed in concert with

724 changing habitats. The diverse array of Middle Jurassic shallow water taxa (longirostrine

725 pliosaurids, teleosauroids, metriorhynchines) declined, and was replaced by an assemblage better

726 suited to higher sea-levels (Pliosaurus, geosaurine and ophthalmosaurid radiations) (Young et al.

727 2012; Benson and Druckenmiller 2014; Foffa et al. 2018). Accordingly, the unique body plan of

728 Bathysuchus and Aeolodon lineage, could be the result of habitat change, and the attempt of a

729 divergent group of teleosauroids to adapt to a new type of environment.

730 Nevertheless, to the extent of our knowledge, teleosauroids never became fully pelagic

731 completing the land-to-sea transition, unlike their relatives the metriorhynchoids. The latter are a

732 textbook example of a secondary adaptation to an aquatic lifestyle, as witnessed by the numerous

733 osteological (e.g. enlarged skull relative to body length, hypocercal tail, modified limb 
734 proportions, paddle-like forelimbs, streamlined bodies, complete loss of osteoderms), and soft

735 tissue adaptations (e.g. enlarged nasal exocrine glands, hypertrophied cranial venous systems,

736 simplified and reduced endocranial sinuses) (e.g. Fraas 1902; Andrews 1913; Young et al. 2011;

737 Brusatte et al. 2016; Herrera et al. 2018). While the Bathysuchus and Aeolodon subclade only

738 shared a few of those adaptations, it still represents an instance of parallel evolution. This

739 demonstrates that different thalattosuchian lineages were dynamically changing their anatomy,

740 lifestyles and habitats during the Jurassic. This may have more generally characterized Mesozoic

741 marine reptile faunas — with the repeated evolution of different types of morphologies and

742 lifestyles in concert with habitat changes (e.g. Benson 2014; Neenan et al. 2017). Finally, more

743 complete specimens (especially from the late Tithonian and Cretaceous) and digital segmentation

744 of the neuroanatomy of these taxa may hold the key to validating or disproving our hypothesis

745 that they were becoming increasingly adapted to a pelagic lifestyle, and offer insights on the

746 mechanisms of secondary land-to-deep-water transitions in tetrapods.

\section{CONCLUSIONS}

748 Here, we describe a new specimen of 'Teleosaurus' megarhinus (DORCM G.05067i-v), figure

749 and re-evaluate the holotype (NHMUK PV OR 43806) and an additional specimen (the LPP

750 specimen), demonstrate that it is indeed a valid species and establish a new monotypic genus,

751 Bathysuchus, for the taxon. Bathysuchus shares numerous rostrum characters with a large

752 unnamed sub-clade of teleosauroids (Steneosaurus brevior, Teleosaurus cadomensis,

753 Platysuchus multiscrobiculatus, Mycterosuchus nasutus and an unnamed taxon from Eastern

754 Asia). This suite of characteristics falsifies the hypothesis that B. megarhinus is a subjective

755 synonym of $S$. leedsi (which lacks all of these characters). Based on the pronounced reduction in

756 dermatocranial and osteoderm ornamentation in Bathysuchus and the closely related Aeolodon 
757 priscus, we hypothesise that by the Late Jurassic at least one lineage of teleosauroids evolved a

758 more pelagic lifestyle, perhaps in response of sea-level raising. This helps to explain the

759 paradoxical discovery of Bathysuchus in the deep-water Dorset succession of the Kimmeridge

760 Clay Formation. Furthermore, in Aeolodon priscus, the post-cranium is well known, and shows

761 skeletal evidence for a pelagic shift. This suggests that metriorhynchids were not the only

762 thalattosuchians to transition from nearshore environments to a fully marine habitat, but that

763 some teleosauroids convergently made the same switch. The future assessment of promising and

764 newly available materials from the Late Jurassic of continental Europe (and particularly the re-

765 description of Aeolodon priscus and 'Steneosaurus' jugleri) is likely to shed light over the

766 interrelationships, evolution and ecology of the peculiar T-clade within Teleosauroidea. 


\section{Acknowledgments}

769

770

771

772

773

774

775

776

777

778

779

780

781

782

783

784

785

786

787

DF, MMJ and MTY should be considered equal first co-authors of this project, because they contributed equally in research time, specimen examination, and writing.

We thank the Photography Department of Natural History Museum (NHMUK) for providing quality photos of NHMUK PV OR 43086. Thanks to Paul Tomlinson and Heather Middleton for help during DF's visit at Dorset County Museum (DORCM). Thanks to M. Riley (CAMSM), X. Xu and L. Zhang (IVPP), G. Garcia and F. Guy (LPP), R. Allain (MNHN), B. Thuy and R. Weis (MNHNL), U. Göhlich (NHMW), S. Maidment (NHMUK) and R. Schoch and E. Maxwell (SMNS) for MMJ's access to collections. We would like to thank Stéphane Jouve, Eric Wilberg, Attila Ösi, and the Editor Hans-Dieter Sues for their detailed reviews and comments that greatly improved the quality of this manuscript.

\section{REFERENCES}

Andrews, C. W. 1909. XXXVIII. - On some new steneosaurs from the Oxford Clay of Peterborough. Annals and Magazine of Natural History 3: 299-308.

DOI:10.1080/00222930908692579.

Andrews, C. W. 1913. A descriptive catalogue of the marine reptiles of the Oxford Clay, Part Two. London: British Museum (Natural History).

Berckhemer, F. 1929. Beiträge zur Kenntnis der Krokodilier des schwäbischen oberen Lias. Neues Jahrbuch für Mineralogie, Geologie und Paläontologie, Beilagenband 64B:1-59. 
788 Benson, R. B. J. 2013. Marine Reptiles. In Grzimek’s Animal Life Encyclopedia, Extinction (N

789

790

791

792

793

794

795

796

797

798

799

800

801

802

803

804

805

806
MacLeod, JD Archibald, P Levin eds). Gale Cengage Learning, Farmington Hills, Michigan, 267-279.

Benson, R.B.J., and Druckenmiller, P.S. 2014. Faunal turnover of marine tetrapods during the Jurassic-Cretaceous transition. Biological Reviews 89: 1-23.

Blake, J. F. 1876. The Yorkshire Lias. John Van Voorst, London.

Brignon, A. 2014. Les dessins originaux de l'«Histoire des crocodiliens renfermés dans le terrain oolithique» d'Étienne Geoffroy Saint-Hilaire. Comptes Rendus Palevol, 13(7): 637-645.

Bronn, H. G. 1841. Über die fossilen Gaviale der Lias-Formation und der Oolithe. Archiv für Naturgeschichte, Berlin 8:77-82.

Bronzati, M., Montefeltro, F. C., and Langer, M. C. 2012. A species-level supertree of Crocodyliformes. Historical Biology 24: 598-606.

Brusatte, S. L., Muir, A., Young, M. T., Walsh, S., Witmer, L., and Steel, L. 2016. The braincase and neurosensory anatomy of an Early Jurassic marine crocodylomorph: implications for crocodilian sinus evolution and sensory transitions. The Anatomical Record 299: 15111530.

Buffetaut, E., Termier, G., and Termier, H. 1981. A teleosaurid (Crocodylia, Mesosuchia) from the Toarcian of Madagascar and its palaeobiological significance. Paläontologische Zeitschrift 55: 313-319. 
807 Buffetaut, E., Rose, J. M., and Vadet, A. 1986. Catalogue commenté des types de crocodiliens 808 fossiles du Musée d'Histoire Naturelle de Boulogne-sur-Mer. Mémoires de la Société 809 Academique Boulonnais, Boulogne 1: 72-85.

810 Buscalioni, A. D., Piras, P., Vullo, R., Signore, M., and Barbera, C. 2011. Early Eusuchia

811

812

813

814

815

816

817

818

819

820

821

822

823

824

825 crocodylomorpha from the vertebrate-rich Plattenkalk of Pietraroia (Lower Albian, southern Apennines, Italy). Zoological Journal of the Linnean Society 163: S199S227. doi: $10.1111 / \mathrm{j} .1096-3642.2011 .00718 . \mathrm{x}$

Chatterjee, S. 1985. Postosuchus, a new thecodontian reptile from the Triassic of Texas and the origin of tyrannosaurs. Philosophical Transactions of the Royal Society of London, Series B 309: 395-460.

Clarac, F., Buffrénil, V. de, Brochu, C., and Cubo, J. 2017. The evolution of bone ornamentation in Pseudosuchia: morphological constraints versus ecological adaptations. Biological Journal of the Linnean Society 121: 395-408.

Clark, J. M. 2011. A new shartegosuchid crocodyliform from the Upper Jurassic Morrison Formation of western Colorado. Zoological Journal of the Linnean Society, https://doi.org/10.1111/j.1096-3642.2011.00719.x

Cox, B. M., and Gallois, R. W. The stratigraphy of the Kimmeridge Clay of the Dorset type area and its correlation with some other Kimmeridgian sequences. Report of the Institute of Geological Sciences, 80/4 
826 Coe, A. L. 1992. The Oxfordian and Portlandian. In Coe, A. L., Hesselbo, S. P., Parkinsson, D.

827 N., and Jenkyins, H. C. (Ed.) Sequence Stratigraphy of the Dorset Jurassic, a field guide.

828 Sequence Stratigraphy of European Basins, CNRS-IFP, Dijon, France 37-81.

829 Coe, A. L. 1995. A comparison of the Oxfordian successions of Dorset, Oxfordshire and

830 Yorkshire. In Taylor, P. D. (Ed.) Field Geology of the British Jurassic 151-172.

831 Cox, B. M. 2001. In Wright, J. K., and Cox, B. M. British Upper Jurassic Stratigraphy,

832

833

834

835

836

837

838

839

840

841

842

843

844

845

846
Geological Conservation Review Series, No. 21, Joint Nature Conservation Committee, Peterborough, 266pp.

Crompton, A. W., and Smith, K. K. 1980. A new genus and species of crocodilian from the Kayenta Formation (Late Triassic?) of Northern Arizona; pp. 193-217 in L. L. Jacobs (ed.), Aspects of Vertebrate History: Essays in Honor of Edwin Harris Colbert. Museum of Northern Arizona Press.

Curtis, K., and Padian, K., 1999, An Early Jurassic microvertebrate fauna from the Kayenta Formation of northeastern Arizona: microfaunal change across the Triassic-Jurassic boundary. PaleoBios 19(2): 19-37.

Delair, J. B. 1958. The Mesozoic reptiles of Dorset. Proceedings of the Dorset Natural History and Archaeological Society 79: 47-72.

Hulke, J. W. 1871. Note on a Fragment of a Teleosaurian snout from Kimmeridige Bay, Dorset. Quarterly Journal of the Geological Society of London 17: 442-443.

Eudes-Deslongchamps, E. 1867-1869. Notes Paléontologiques. Caen and Paris, France, 320-392 pp. 
847 Eudes-Deslongchamps, E. 1869. Mémoire sur les Téléosauriens. Bulletin de la Société 848 Linnéenne de Normandie, 2(3): 124-221.

849

850

851

852

853

854

855

856

857

858

859

860

861

862

863

864

865

866

867

Fanti, F. Miyashita, T., Cantelli, L., Mnasri, F., Dridi, J., Contessi, M., and Cau, A. 2016. The largest thalattosuchian (Crocodylomorpha) supports teleosaurid survival across the Jurassic-Cretaceous boundary. Cretaceous Research 61: 263-274.

Fernández, M. S., and Gasparini, Z. 2008. Salt glands in the Jurassic metriorhynchid Geosaurus: implications for the evolution of osmoregulation in Mesozoic marine crocodyliforms. Naturwissenschaften 95(1): 79-84.

Fitzinger, L. J. F. J. 1843. Systema Reptilium. Vindobonae: Braumüller et Seidel Press, Wien, Austria.

Foffa, D., Young, M. T., and Brusatte, S. L. 2015. Evidence of macrophagous teleosaurid crocodylomorphs in the Corallian Group (Oxfordian, Late Jurassic) of the UK. PeerJ 3:e1497.

Foffa, D., Young, M. T., and Brusatte, S. L. 2018. Filling the Corallian gap: new information on Late Jurassic marine reptile faunas from England. Acta Palaeontologica Polonica 63: $287-313$.

Fraas, E. 1901. Die Meerkrokodile (Thalattosuchia n. g.) eine neue Sauriergruppe der Juraformation. Jahreshefte des Vereins für vaterländische Naturkunde in Württemberg $57: 409-418$.

Fraas, E. 1902. Die Meer-Krocodilier (Thalattosuchia) des oberen Jura unter specieller Berücksichtigung von Dacosaurus und Geosaurus. Paleontographica 49: 1-72 
868 Gallois, R. W. 2004. The Kimmeridge Clay: the most intensively studied formation in Britain. 869 Open University Geological Journal 25: 33-38.

870 Geoffroy Saint-Hilaire, E. 1831. Recherches sur de grands sauriens trouvés à l'état fossile aux

871

872

873

874

875

876

877

878

879

880

881

882

883

884

885

886

887

888 confins maritimes de la Basse-Normandie, attribués d'abord au crocodile, puis déterminés sous les noms de Teleosaurus et Steneosaurus. Mémoires de l'Académie des Sciences 12: 1138.

Godefroit, P., Vignaud, P., and Lieger, A. 1995. Un Teleosauridae (Reptilia) du Bathonien Superieur Lorrain (France) Bulletin de la Société belge de Géologie, 104 (1-2): 91-107.

Goloboff, P. A., Farris, J. S., and Nixon, K. C. 2008. TNT, a free program for phylogenetic analysis. Cladistics 24: 774-786.

Goloboff, P. A., and Catalano, S. A. 2016. TNT version 1.5, including a full implementation of phylogeneticmorphomet rics. Cladistics 32: 221-238.

Hay, O. P. 1930. Second bibliography and catalogue of the fossil vertebrata of North America 2. Carnegie Institute Washington Press, Washington, DC. Jäeger CF. 1828. Über die fossile Reptilien, welche in Württemberg aufgefunden worden sind. Stuttgart: J. B. Metzler.

Hantzpergue, P., and Lafaurie, G. 1983. Le Kimméridgien quercynois: un complément biostratigraphique du Jurassique supérieur d'Aquitaine. Géobios 16(1):601-609.

Hantzpergue, P. 1989. Les ammonites kimméridgiennes du haut-fond d'Europe occidentale, Cahiers de paléontologie, CNRS, 1989, p. 1-428.

Herrera Y., Fernández, M. S., and Gasparini, Z. 2013. The snout of Cricosaurus araucanensis: a case study in novel anatomy of the nasal region of metriorhynchids. Lethaia 46(3): 331-340 
889 Herrera, Y., Fernández, M. S., Lamas, G. S., Campos, L., Talevi, M., and Gasparini, Z. 2017.

890 Morphology of the sacral region and reproductive strategies of Metriorhynchidae: a counter-

891 inductive approach. Earth and Environmental Science Transactions of the Royal Society of

892 Edinburgh 106(4): 247-255

893 Herrera Y., Leardi, J.M., and Fernández, M.S. 2018. Braincase and endocranial anatomy of two 894 thalattosuchian crocodylomorphs and their relevance in understanding their adaptations to 895 the marine environment. PeerJ 6:e5686 https://doi.org/10.7717/peerj.5686

896

897

898

899

900

901

902

903

904

905

906

907

908

Hulke, J. W. 1871. Note on a Fragment of a Teleosaurian snout from Kimmeridige Bay, Dorset. Quarterly Journal of the Geological Society of London 17: 442-443.

Iijima M., Kubo T., and Kobayashi Y. 2018. Comparative limb proportions reveal differential locomotor morphofunctions of alligatoroids and crocodyloids. Royal Society open science 5: 171774. http://dx.doi.org/10.1098/rsos.171774

Jäger, C. F. 1828. Über die fossile Reptilien, welche in Württemberg aufgefunden worden sind. Stuttgart: J. B. Metzler.

Johnson, M. M., Young, M. T., Steel, L., and Lepage, Y. 2015. Steneosaurus edwardsi (Thalattosuchia, Teleosauridae), the largest known crocodylomorph of the Middle Jurassic. Biological Journal of the Linnean Society 115: 911-918.

Johnson, M. M., Young, M. T., Steel, L., Foffa, D., Smith, A. S., Hua, S., Havlik, P., Howlett, E. A., and Dyke, G. 2017. Re-description of 'Steneosaurus' obtusidens Andrews, 1909, an unusual macrophagous teleosaurid crocodylomorph from the Middle Jurassic of 
909

910

911

912

913

914

915

916

917

918

919

920

921

922

923

924

925

926

927

928

929

England. Zoological Journal of the Linnean Society

zlx035, https://doi.org/10.1093/zoolinnean/zlx035

Johnson, M.M. Young, M.T., Brusatte, S.L., Thuy, B., and Weis, R. 2018. A catalogue of teleosauroids (Crocodylomorpha: Thalattosuchia) from the Toarcian and Bajocian (Jurassic) of southern Luxembourg. Historical Biology DOI:

$10.1080 / 08912963.2018 .1427090$

Jouve, S., Mennecart, B., Douteau, J, and Jalil, N.-E. 2016. The oldest durophagous teleosaurid (Crocodylomorpha, Thalattosuchia) from the Lower Bathonian of Central High Atlas, Morocco. Palaeontology 59: 863-876.

Kuhn, O. 1936. Crocodilia. In: Fossilium Catalogus, Animalia. W. Quenstedt Ed, Berlin, 1, 75: 1-144.

Lamouroux, M. 1820. Sur le crocodile fossile trouve' dans les carrie`res du bourg d'Allemagne, a` un quart de lieue de Cean. Annales Générales des Sciences Physiques 3:160-164.

Lennier, G. 1887. Description des fossiles du Cap de la Hève. Bulletin de la Société Géologique de Normandie. Le Havre 12: 17-98.

Lepage, Y., Buffetaut, E., Hua, S., Martin, J.E., and Tabouelle, J. 2008. Catalogue descriptif, anatomique, géologique et historique des fossiles présentés à l'exposition Les Crocodiliens fossiles de Normandie. Bulletin de la Société Géologique de Normandie et des Amis du Muséum du Havre 95: 5-152.

Li, J. 1993. A new specimen of Peipehsuchus teleorhinus from Ziliujing Formation of Daxion, Sichuan. Vertebrata PalAsiatica 31: 85-94. 
930 Lydekker, R. 1888. Catalogue of the Fossil Reptilia and Amphibia in the British Museum 931 (Natural History). Part I. Containing the Orders Ornithosauria, Crocodilia, Dinosauria, 932 Squamata, Rhynchocephalia, and Proterosauria. British Museum (Natural History): $933 \quad$ London, 1-309.

934 Martin, J. E., and Vincent, P. 2013. New remains of Machimosaurus hugii von Meyer, 1837 935 (Crocodylia, Thalattosuchia) from the Kimmeridgian of Germany. Fossil Record 16: $179-196$. Journal of Vertebrate Paleontology 7: 121-137.

McArthur, A. D, Hartley, A. J., and Jolley, D.W. 2013. Stratigraphic development of an Upper Jurassic deep marine syn-rift succession, Inner Moray Firth Basin, Scotland. Basin Research 25(3): 285-309.

Meyer, H von. 1845. System er fossilen Saurier, Mittheilung an Prof. Bronn gerichtet. Neues Jahrbuch für Mineralogie Abhandlungen, Stuttgart 689-691.

944 Mueller-Töwe, I. J. 2006. Anatomy, phylogeny, and palaeoecology of the basal thalattosuchians 945 (Mesoeucrocodylia) from the Liassic of Central Europe. Unpublished $\mathrm{PhD}$ thesis, $946 \quad$ Universität Mainz, Germany.

947 Neenan, J. M., Reich, T., Evers, S. W., Druckenmiller, P. S., Voeten, D. F. A. E., Choiniere, J. 948 N., Barrett, P. M., Pierce S. E., and Benson, R. B. J. 2017. Evolution of the 949 sauropterygian labyrinth with increasingly pelagic lifestyles. Current Biology 27(24): 3852-3858.e3 
951 Nesbitt, N.J. 2011. The early evolution of archosaurs: relationships and the origin of major 952 clades. Bulletin of the American Museum of Natural History 352:1-292.

953 Ösi, A., Young, M. T., Galácz, A., and Rabi, M. 2018. A new large-bodied thalattosuchian crocodyliform from the lower Jurassic (Toarcian) of Hungary, with further evidence of the mosaic acquisition of marine adaptations in Metriorhynchoidea. PeerJ 6:e4668.

956

957

958

959

960

961

962

963

964

965

966

967

968

969

970

971

Pierce, S. E., Angielczyk, K. D., and Rayfield, E. J. 2009. Morphospace occupation in thalattosuchian crocodylomorphs: skull shape variation, species delineation and temporal patterns. Palaeontology 52: 1057-1097.

Ristevski, J., Young, M. T., Andrade, M. B. and Hastings, A. K. 2018. A new species of Anteophthalmosuchus (Crocodylomorpha, Goniopholididae) from the Lower Cretaceous of the Isle of Wight, United Kingdom, and a review of the genus. Cretaceous Research 84: 340-383.

Sauvage, M. H. E. 1872. Note sur les reptiles fossiles: Bulletin de la Société géologique de France, 3rd series, n. 1, p. 365-386.

Sauvage, M. H. E. 1874. Mémoires sur les Dinosauriens et les Crocodiliens des terrains jurassiques de Boulogne-sur-Mer. Mémoires de la Société Géologique de France, Paris 10: $1-58$.

Sauvage, H.-E., and Liénard, F. 1879. Memoire sur le genre Machimosaurus. Mémoires de la Société Géologique de France, 3ème série 4: 1-31.

Savalle, É. 1876. Note sur une tête de Teleosaurus trouvée à Bléville. Bulletin de la Société géologique de Normandie, tome 3: 52-57, 1 pl. 3. 
972 Schaefer, K., Püntener, C., and Billon-Bruyat, J.-P. 2018. Vertébrés mésozoïques - Crocodiliens.

973 Office de la culture - Paléontologie A16, Porrentruy, 184 p. (Catalogues du patrimoine

974 paléontologique jurassien - A16).

975 Schwarz, D., Frey, E., and Martin, T. 2006. The postcranial skeleton of the Hyposaurinae 2274

976 (Dyrosauridae; Crocodyliformes). Palaeontology 49: 695-718.

977 Seeley, H. G. 1869. Index to the Fossil Remains of Aves, Ornithosauria and Reptilia, from the

978 Secondary System of Strata Arranged in the Woodwardian Museum of the University of

979 Cambridge. Deighton, Bell \& Co., Cambridge.

980 Steel, R. 1973. Crocodylia. In: Encyclopedia of Palaeoherpetology (edit. Kuhn, O.). Gustav

981 Fischer, Stuttgart, Part 16: 1-16.

982 Vignaud, P., Lange-Badre, B., Hantzpergue, P., Dutrieux, M., and Maury G. 1993. Découverte

983 d'un crâne de Teleosauridae dans la Zone à Eudoxus du Kimméridgien supérieur

984 quercynois (France). Comptes rendus de l'Académie des Sciences, Paris 2: 1509-1514.

985 Vignaud, P. 1995. Les Thalattosuchia, crocodiles marins du Mésozoique: Systématique

986 phylogénétique, paléoécologie, biochronologie et implications paléogéographiques.

987 Unpublished $\mathrm{PhD}$ thesis, Université de Poitiers, 410 pp.

988 Vignaud, P. 1997. La morphologie dentaire des Thalattosuchia (Crocodylia, Mesosuchia).

$989 \quad$ Palaeovertebrata 26: 35-59.

990 von Sömmerring, S. T. 1814. Über den Crocodilus priscus, oder ein in Baiern versteint

991 gefundenes schmalkie-feriges Krokodil, Gavial der Vorwelt. Denkschriften der 

Naturwissenschaften, 9-82.

994 Weedon, G. P., Coe, A. L., and Gallois, W. 2004. Cyclostratigraphy, orbital tuning and inferred productivity for the type Kimmeridge Clay (Late Jurassic), Southern England. Journal of the

Westphal, F. 1961. Zur Systematik der deutschen und englischen Lias-Krokodilier. Neues Jahrbuch für Geologie und Paläontologie 113:207-218.

999

1000

1001

1002

1003

1004

1005

1006

1007

1008

1009

1010

1011 Geological Society 161: 655-666, https://doi.org/10.1144/0016-764903-073

Westphal, F. 1962. Die krokodilier des Deutschen und Englischen oberen Lias. Palaeontographica, Abteilung A 116: 23-118.

Wu, X.-C., Russell, A. P., and Cumbaa, S. L. 2001. Terminonaris (Archosauria: Crocodyliformes): new material from Saskatchewan, Canada, and comments on its phylogenetic relationships. Journal of Vertebrate Paleontology 21:492-514.

Young, M. T., and M. B. Andrade. 2009. What is Geosaurus? Redescription of Geosaurus giganteus (Thalattosuchia: Metriorhynchidae) from the Upper Jurassic of Bayern, Germany. Zoological Journal of the Linnean Society 157(3):551-585. Doi: 10.1111/j.1096-3642.2009.00536.x

Young, M. T., Andrade, M. B., Etches, S., and Beatty B. L. 2013. A new metriorhynchid crocodylomorph from the Lower Kimmeridge Clay Formation (Late Jurassic) of England, with implications for the evolution of dermatocranium ornamentation in Geosaurini. Zoological Journal of the Linnean Society 169(4):820-848. 
1012 Young, M. T., Bell, M. A., Andrade, M. B., and Brusatte, S. L. 2011. Body size estimation and

1013

1014

1015

1016

1017

1018

1019

1020

1021

1022

1023

1024

1025

1026

1027

1028

1029

1030

1031

evolution in metriorhynchid crocodylomorphs: implications for species diversification and niche partitioning. Zoological Journal of the Linnean Society 163(4): 1199-1216.

Young, M. T., Brusatte, S. L., Andrade, M. B., Desojo, J. B., Beatty, B. L., Steel, L., Fernández, M. S., Sakamoto, M., Ruiz-Omeñaca, J. I., and Schoch, R. R. 2012. The cranial osteology and feeding ecology of the metriorhynchid crocodylomorph genera Dakosaurus and Plesiosuchus from the Late Jurassic of Europe. PLoS ONE 7 (9): e44985.

Young, M. T., Hua, S., Steel, L., Foffa, D., Brusatte, S. L., Thüring, S., Mateus, O., RuizOmeñaca, J. I., Havlik, P., Lepage, Y., and Andrade, M. B. 2014a. Revision of the Late Jurassic teleosaurid genus Machimosaurus (Crocodylomorpha, Thalattosuchia). Royal Society Open Science, 1, 140222.

Young, M. T., Márton, R., Bell, M. A., Foffa, D., Steel, L., Sachs, S., and Peyer. K. 2016. Bigheaded marine crocodyliforms and why we must be cautious when using extant species as body length proxies for long-extinct relatives. Palaeontologia Electronica 19(3): 1-14.

Young, M. T., and Steel, L. 2014. Evidence for the teleosaurid crocodylomorph genus Machimosaurus in the Kimmeridge Clay Formation (Late Jurassic) of England, Historical Biology: An International Journal of Paleobiology 26(4): 472-479.

Young, M. T., Steel, L., Brusatte, S. L., Foffa, D., and Lepage, Y. 2014b. Tooth serration morphologies in the genus Machimosaurus (Crocodylomorpha, Thalattosuchia) from the Late Jurassic of Europe. Royal Society Open Science 1, 140269. 
Figure 1

Stratigraphic and palaeogeographic distribution of Late Jurassic (Kimmeridgian - early Tithonian) Bathysuchus megarhinus.

Map modified from Ron Blakey @ (http://cpgeosystems.com/).

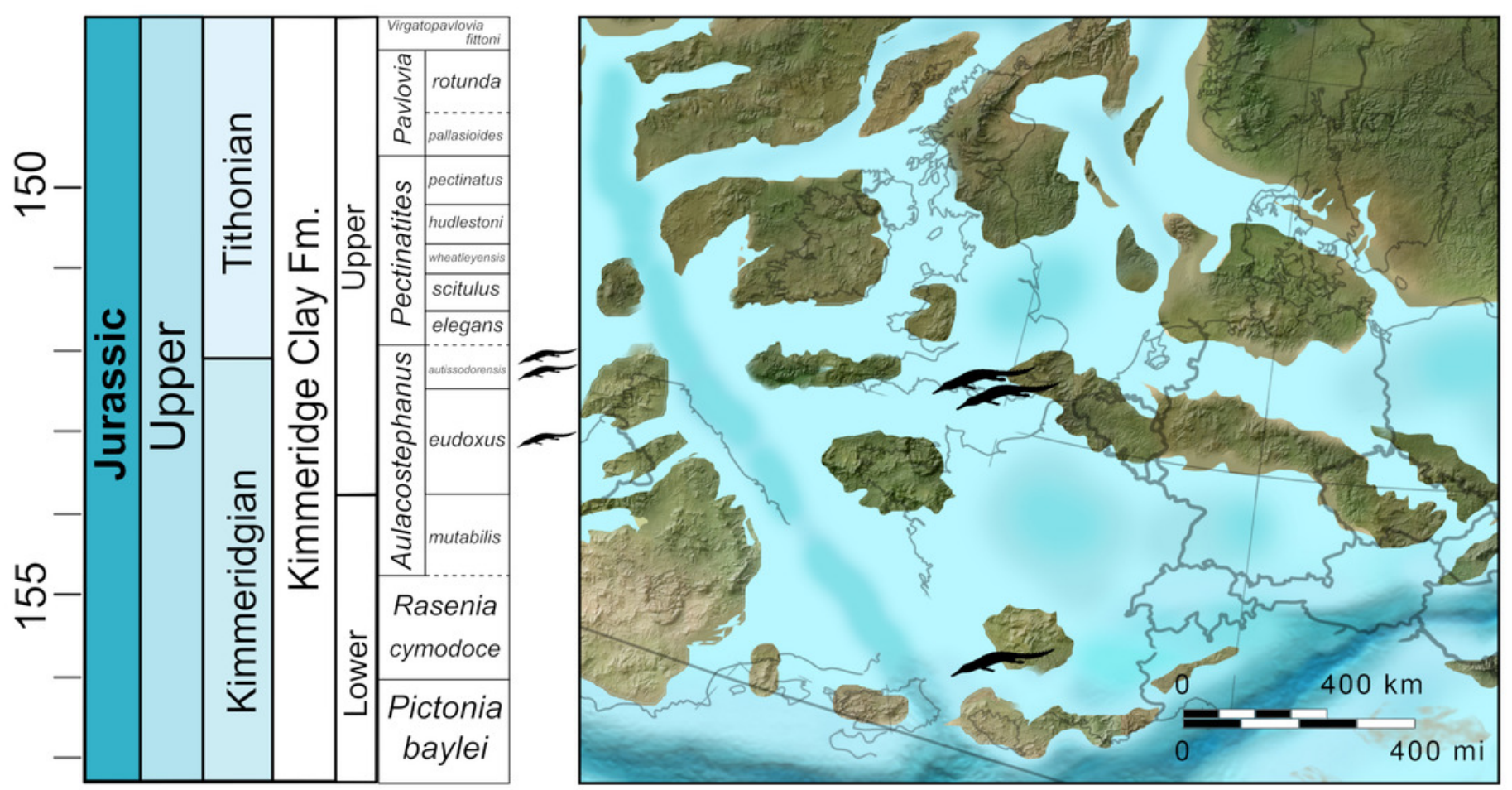




\section{Figure 2}

NHMUK PV OR 43086, holotype of Bathysuchus megarhinus gen. et. sp. nov. from the Kimmeridgian of Kimmeridge Bay, Dorset, UK, and interpretative drawings.

A, G, middle and anterior rostrum in dorsal view. B, H, rostrum in left lateral view. C, I, rostrum in ventral view. $\mathrm{D}, \mathrm{J}$, rostrum in right lateral ventral view. $\mathrm{E}, \mathrm{K}$, maxillae in posterior view. F, L, premaxilla in anterior view. Scale bar equals $30 \mathrm{~cm}$. (C) The Trustees of the Natural History Museum, London. 
A
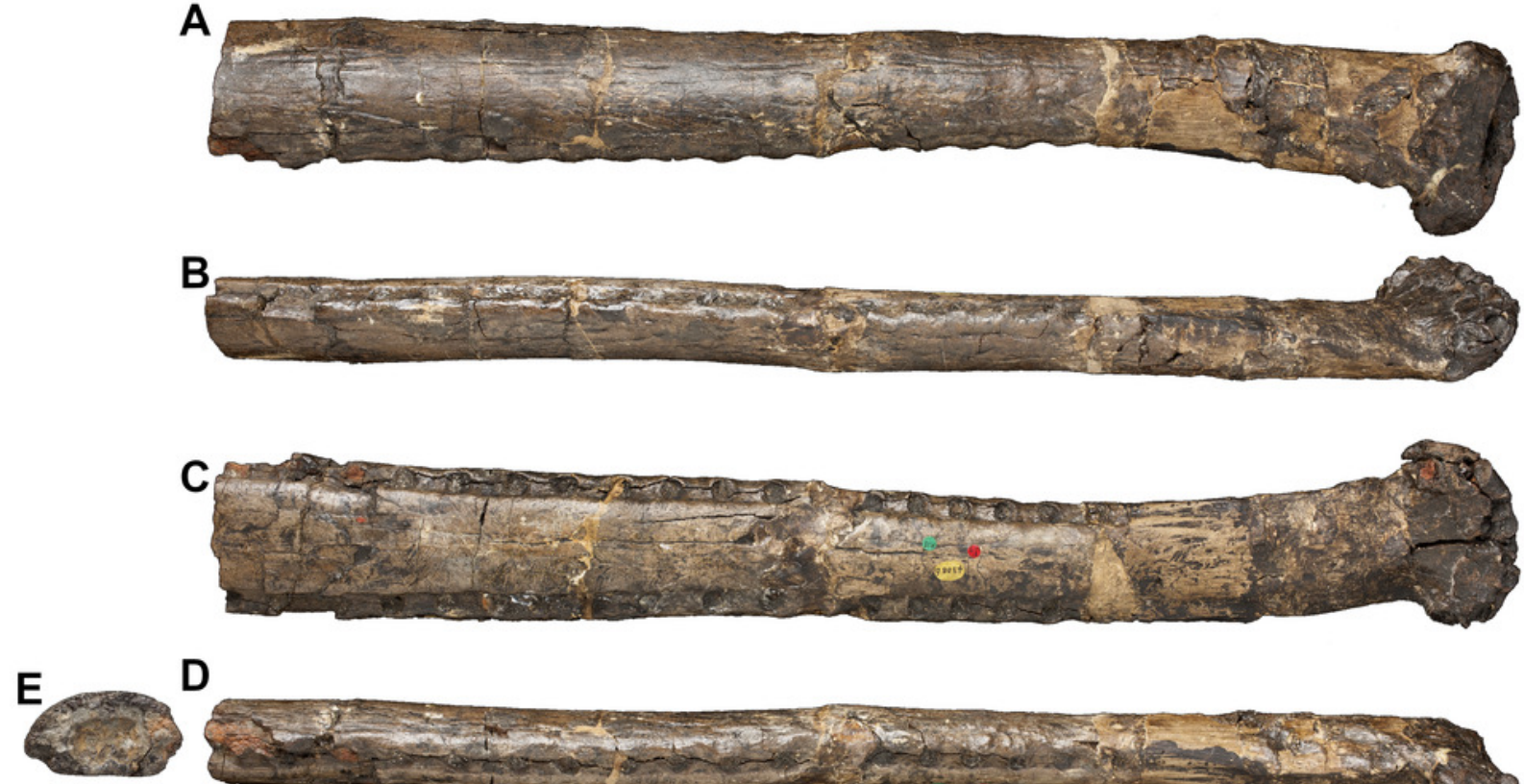

D

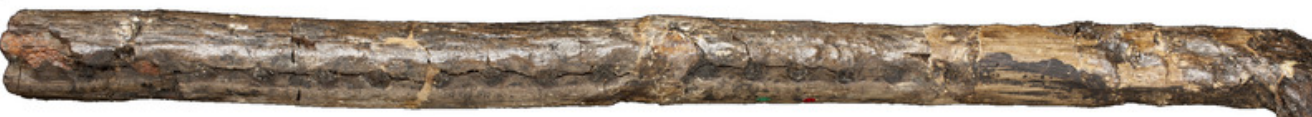

\section{$\mathbf{F}$}

G
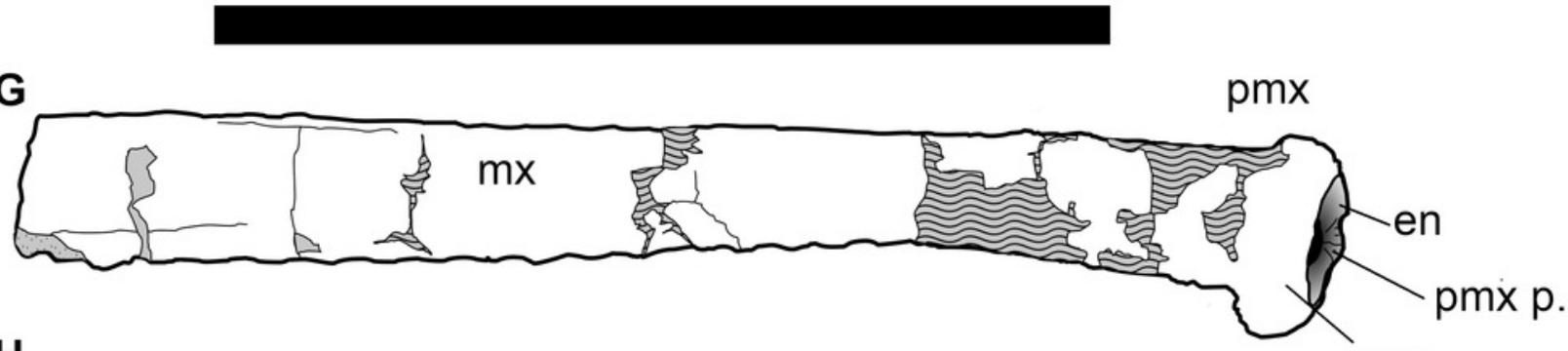

H

$p m x$
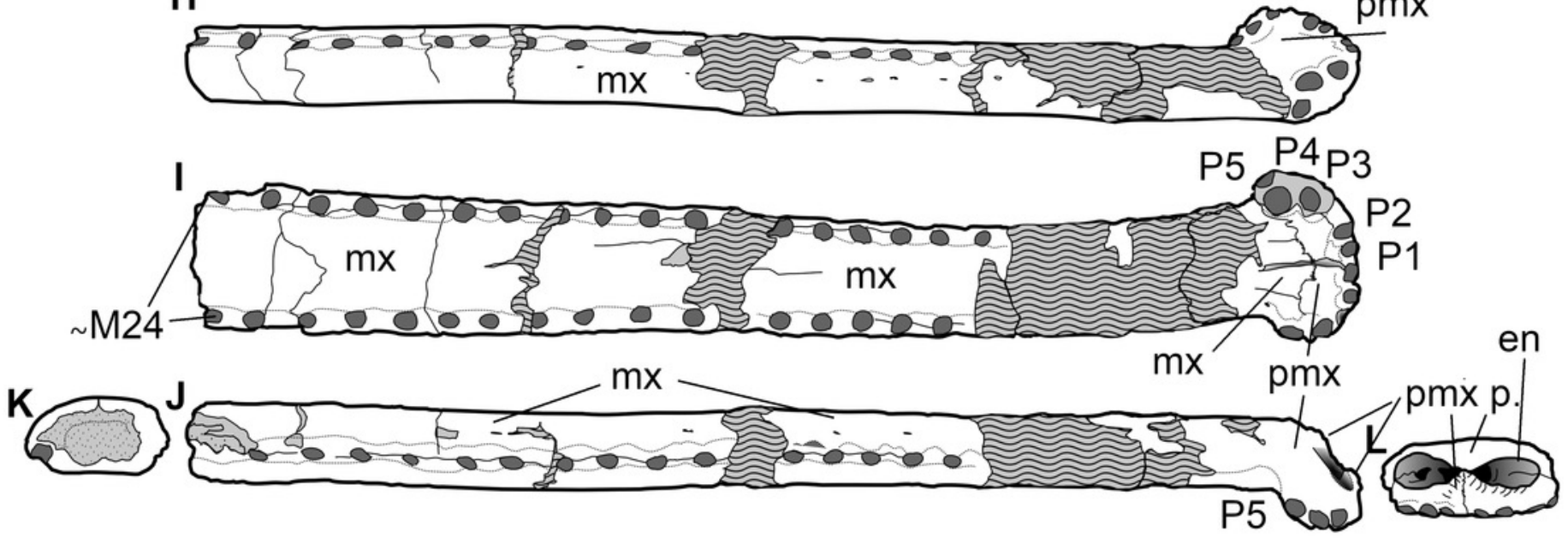


\section{Figure 3}

DORCM G.05067i, anterior rostrum of referred specimen of Bathysuchus megarhinus gen. et. sp. nov. from the Kimmeridgian of Kimmeridge Bay, Dorset, UK, and interpretative drawings.

A, F, anterior maxillae and premaxillae in left dorsal view. B, G, anterior maxillae and premaxillae in left lateral view. C, H, anterior maxillae and premaxillae in ventral view. D, I, anterior maxillae and premaxillae in in right lateral view. E, J, premaxilla in anterior view. Scale bar equals $10 \mathrm{~cm}$. 
A
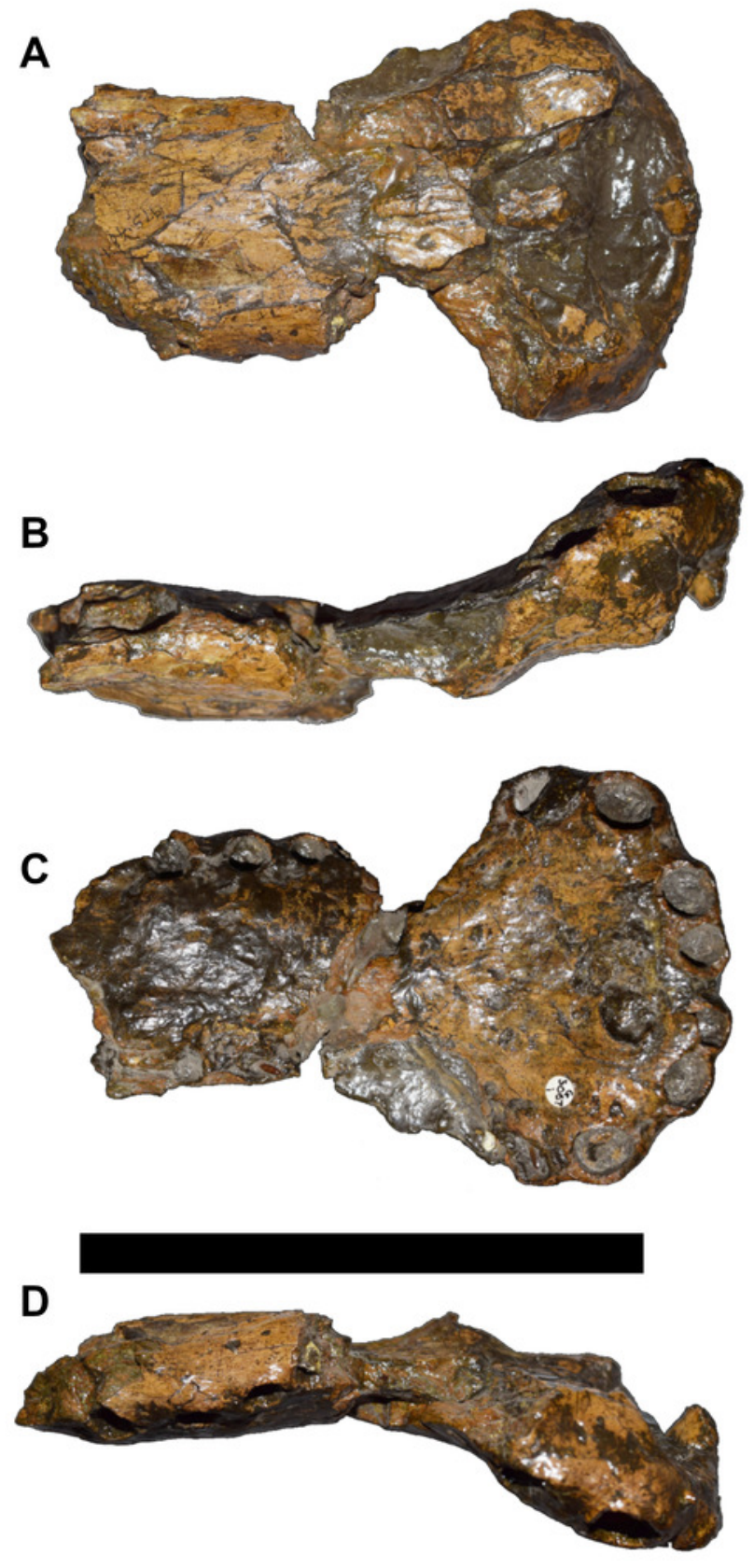

E

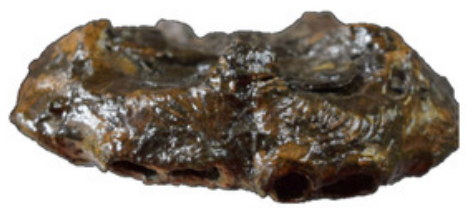

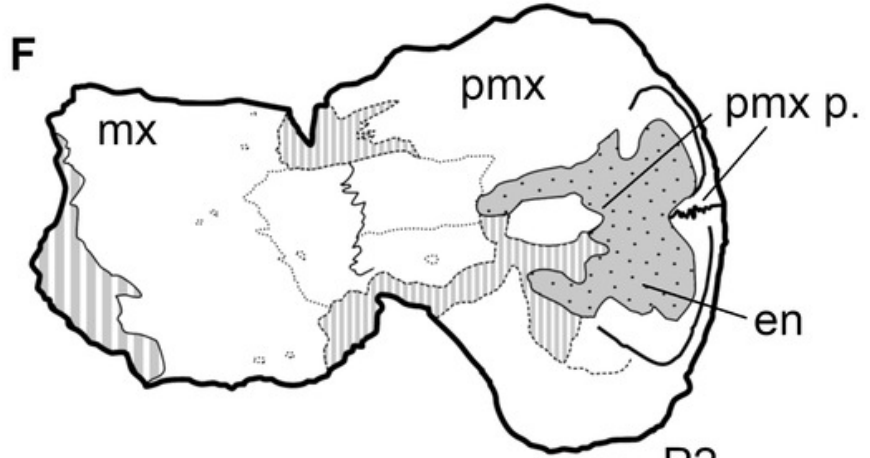
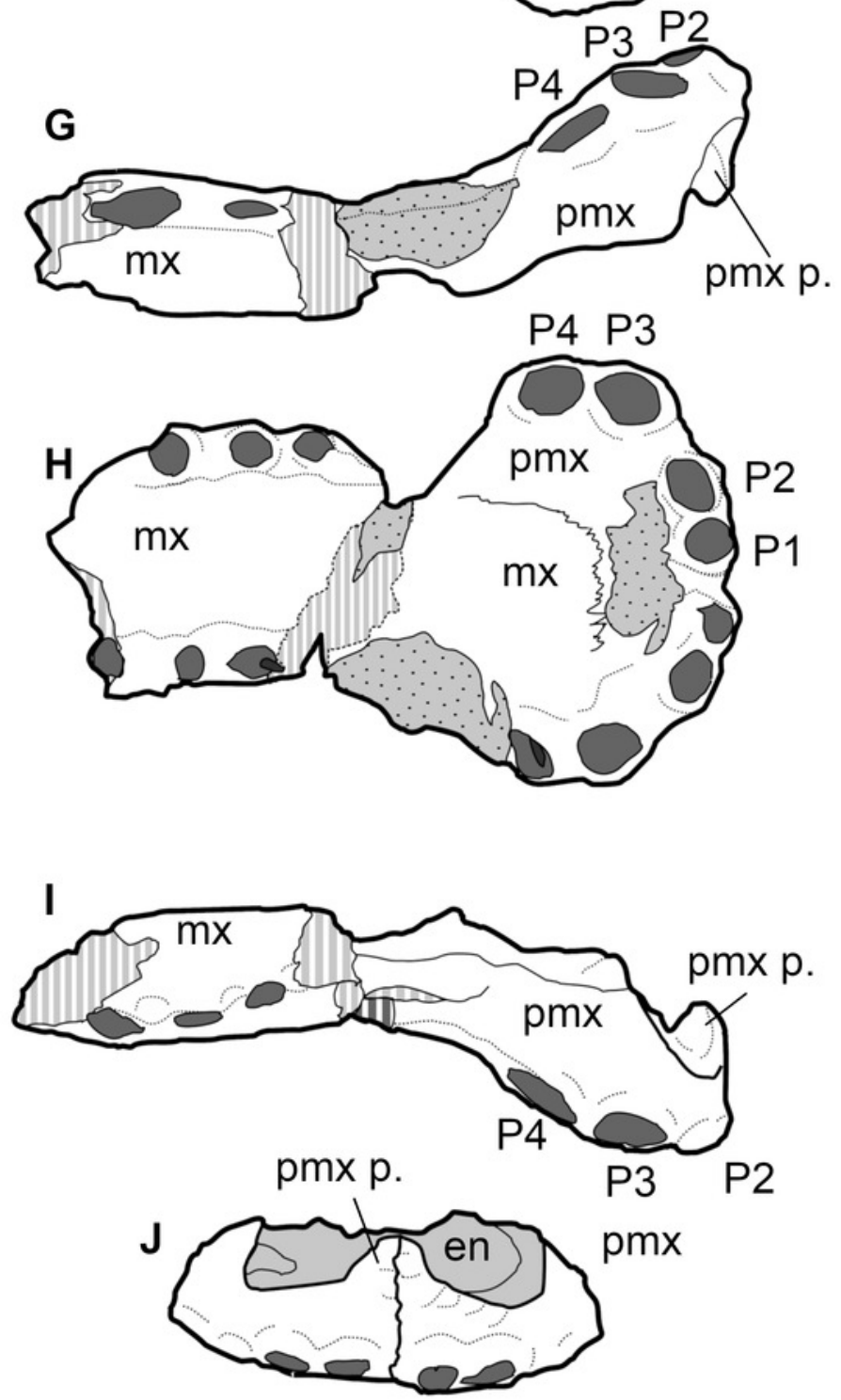


\section{Figure 4}

LPP specimen, anterior rostrum of referred specimen of Bathysuchus megarhinus gen. et. sp. nov. from the Upper Kimmeridgian of Franculès, Quercy, France, and interpretative drawings.

A, E, anterior maxillae and premaxillae in dorsal view. B, F, anterior maxillae and premaxillae in left lateral view. C, G, anterior maxillae and premaxillae in ventral view. D, H, anterior maxillae and premaxillae in right lateral view. Scale bar equals $10 \mathrm{~cm}$. 
A

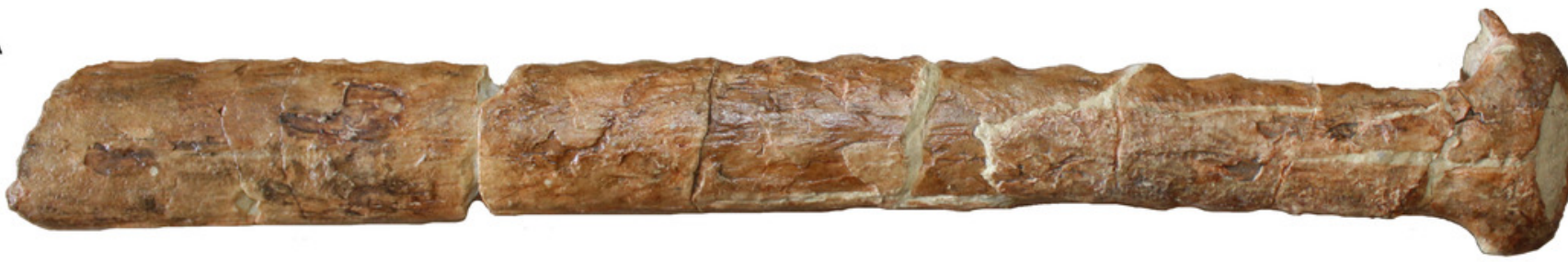

B

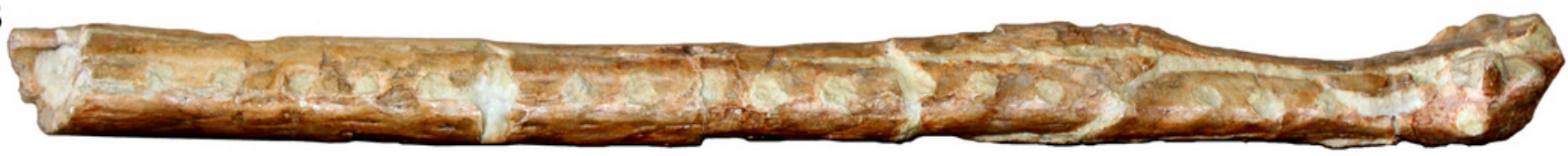

C

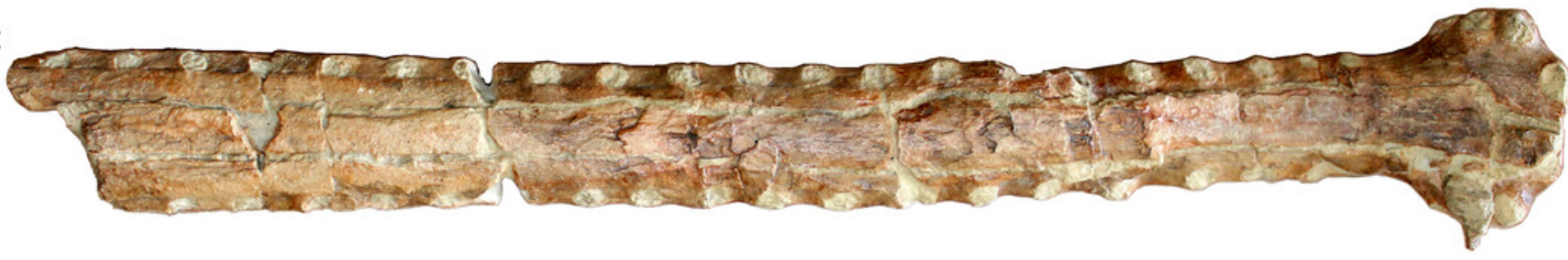

D

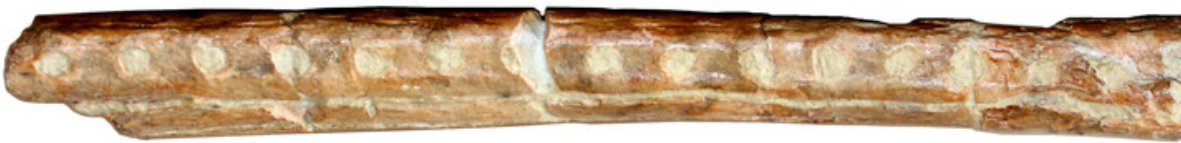

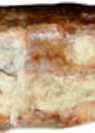

E

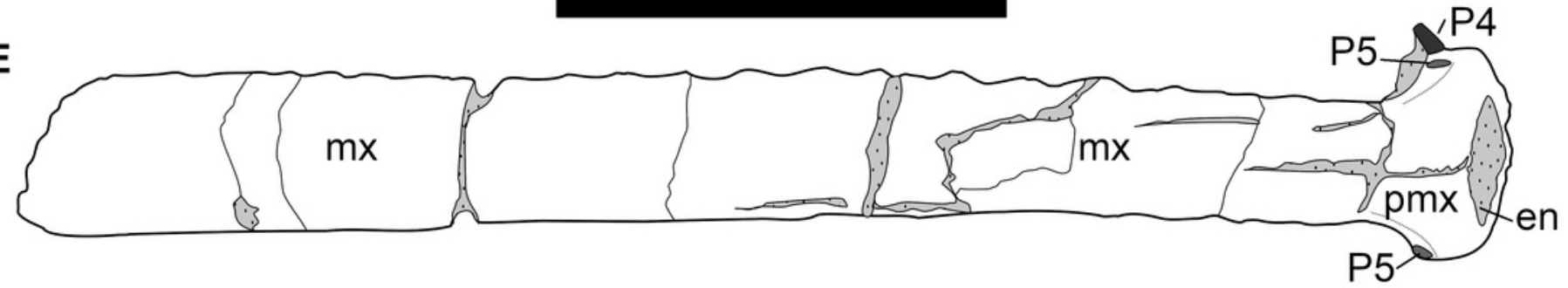

F

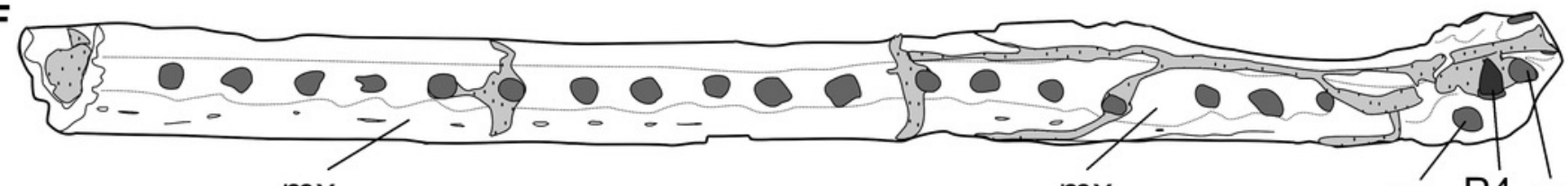

G

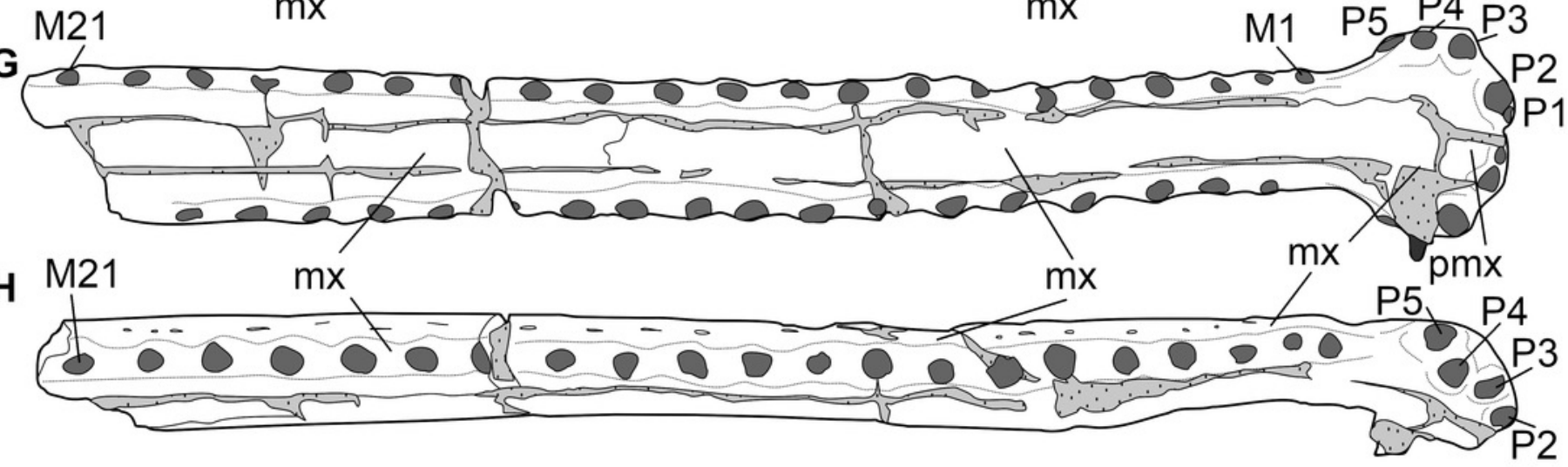




\section{Figure 5}

LPP specimen, orbital and posterior skull of referred specimen of Bathysuchus megarhinus gen. et. sp. nov. from the Upper Kimmeridgian of Franculès, Quercy, France, and interpretative drawings.

A, F, skull in dorsal view. B, G, skull in right lateral view. C, H, skull in ventral view. D, I, skull in right lateral view. E, J, skull in posterior view. Scale bar equals $10 \mathrm{~cm}$. 


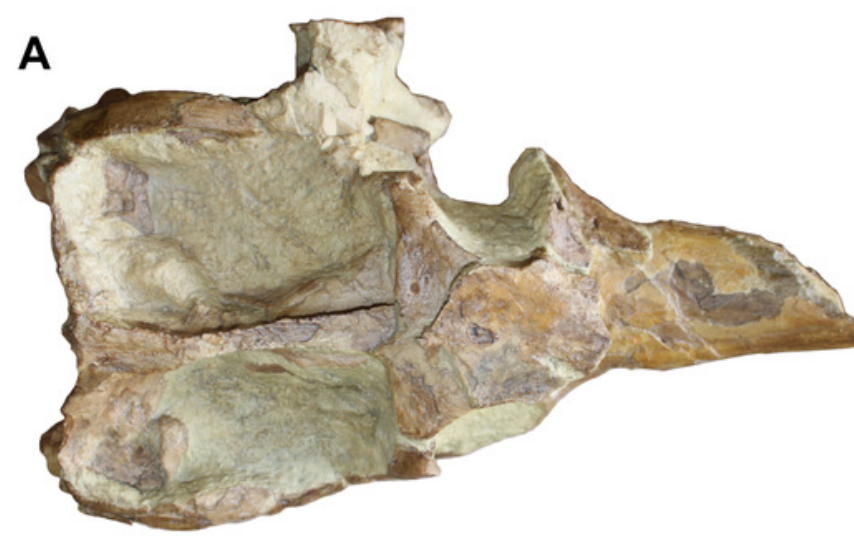

B

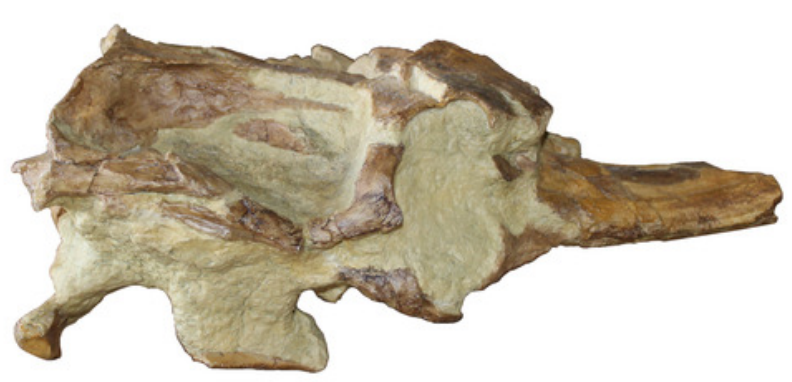

C

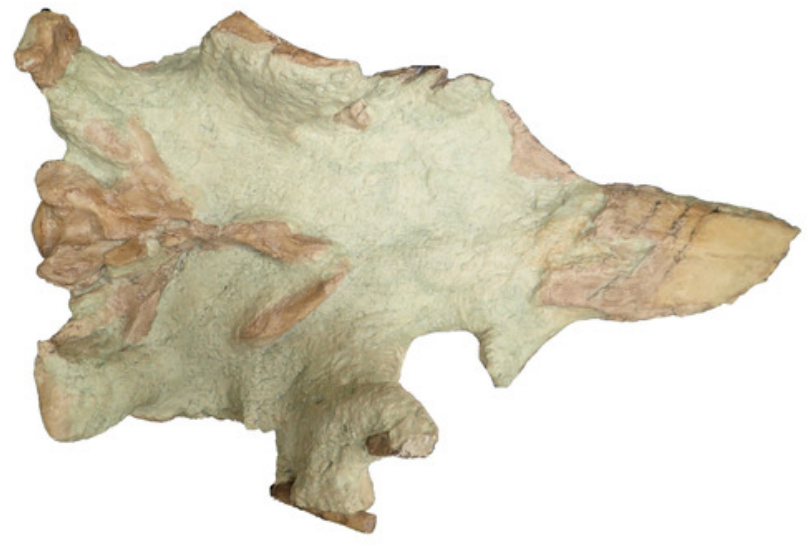

D

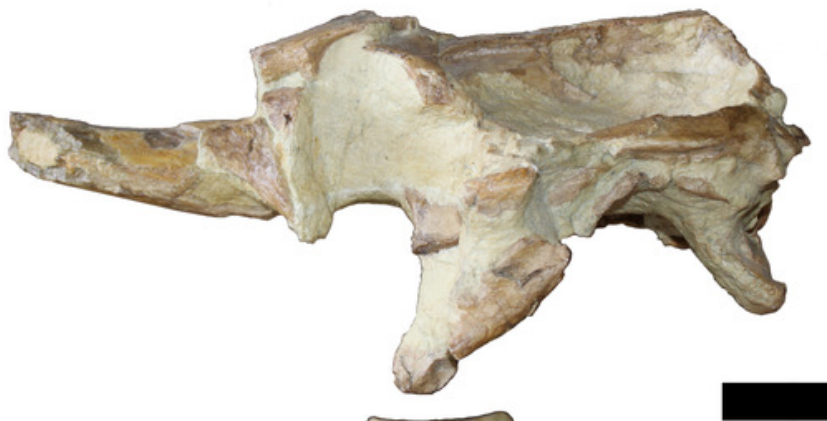

E

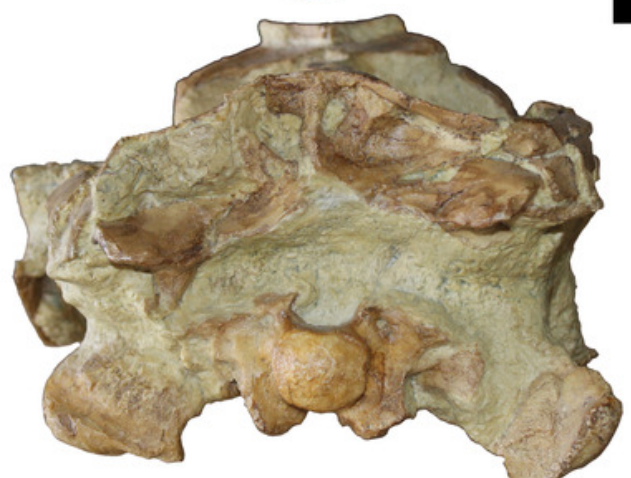

PeerJ reviewing PDF | (2018:02:25493:2:1:NEW15 Feb 2019)
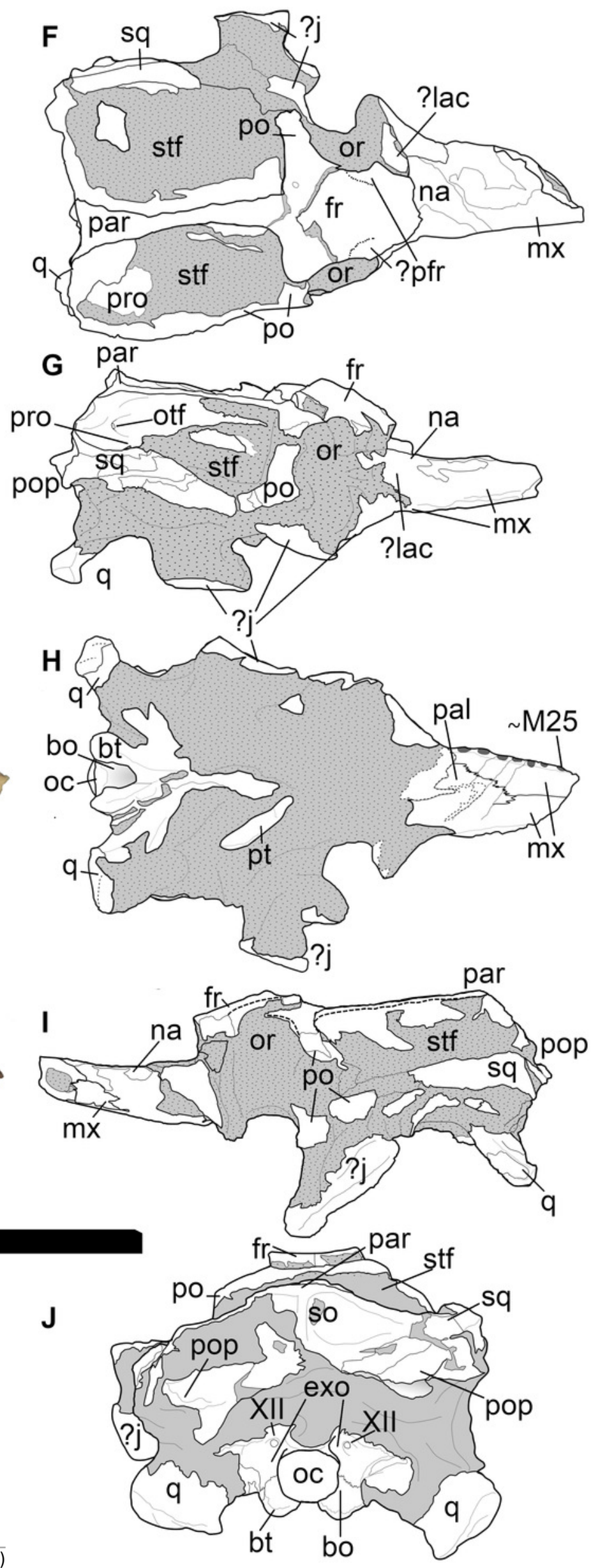
Figure 6

LPP specimen, mandibular symphysis of referred specimen of Bathysuchus megarhinus gen. et. sp. nov. from the Upper Kimmeridgian of Franculès, Quercy, France, and interpretative drawings.

A, C, mandible in dorsal view. B, D, mandible in left lateral view. Scale bar equals $10 \mathrm{~cm}$.

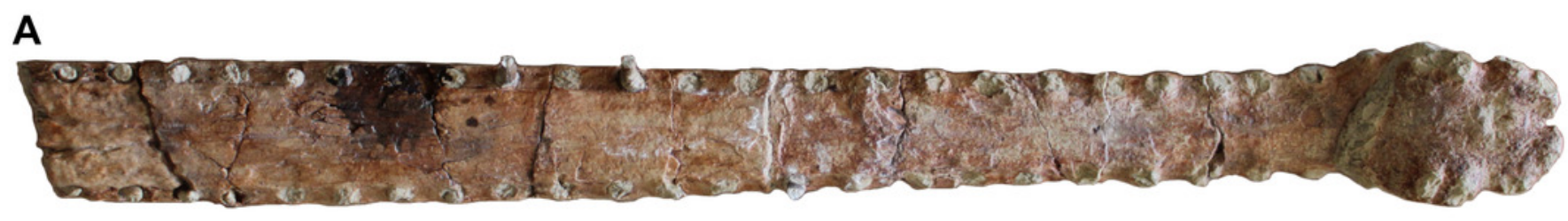

B
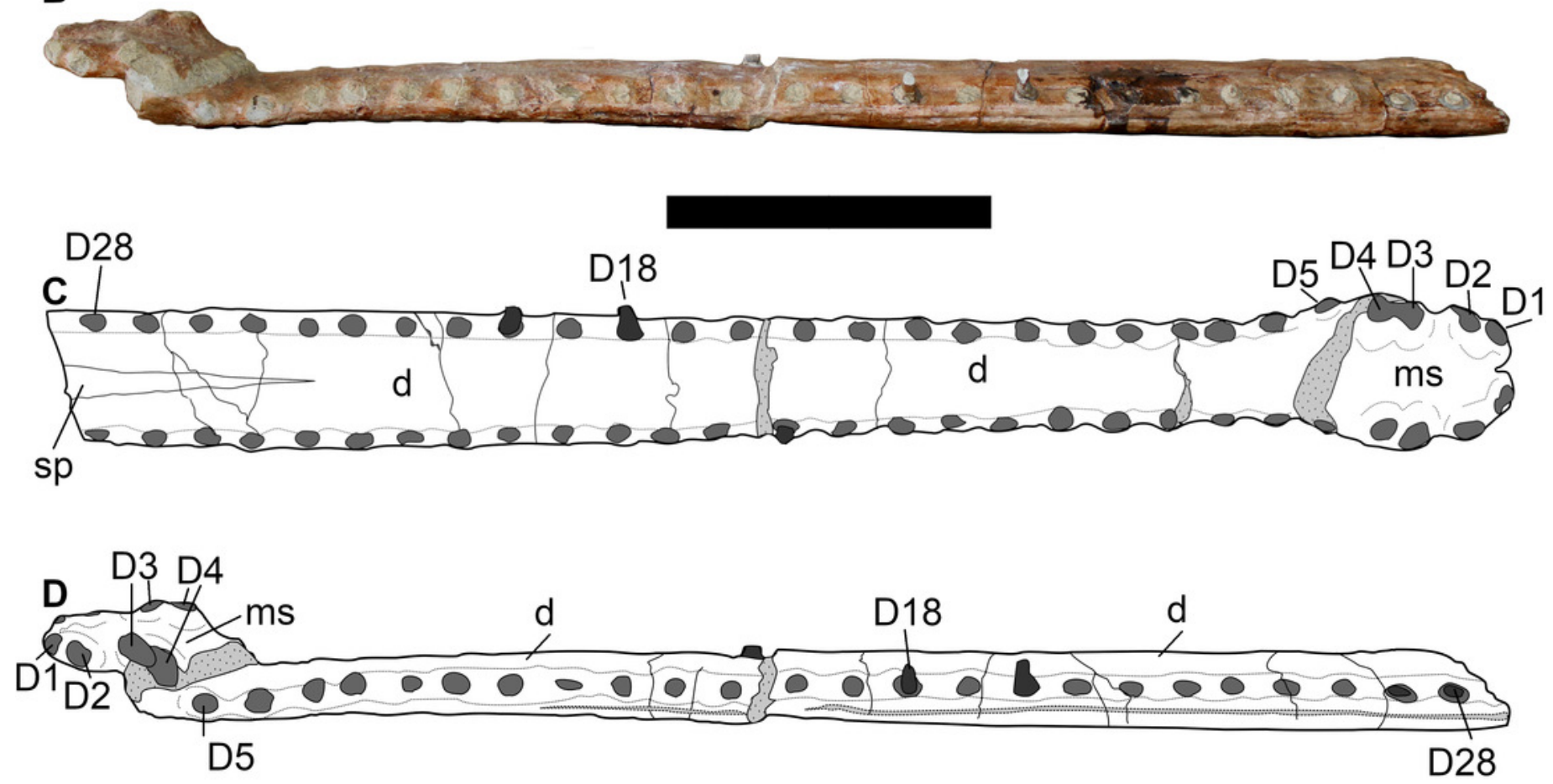


\section{Figure 7}

DORCM G.05067iv tooth of Bathysuchus megarhinus gen. et. sp. nov.

A, tooth in labial view. B, tooth medial-mesial view. C, tooth in lingual view. $D$, tooth in mesial-medial view. Scale bar equals $3 \mathrm{~cm}$.
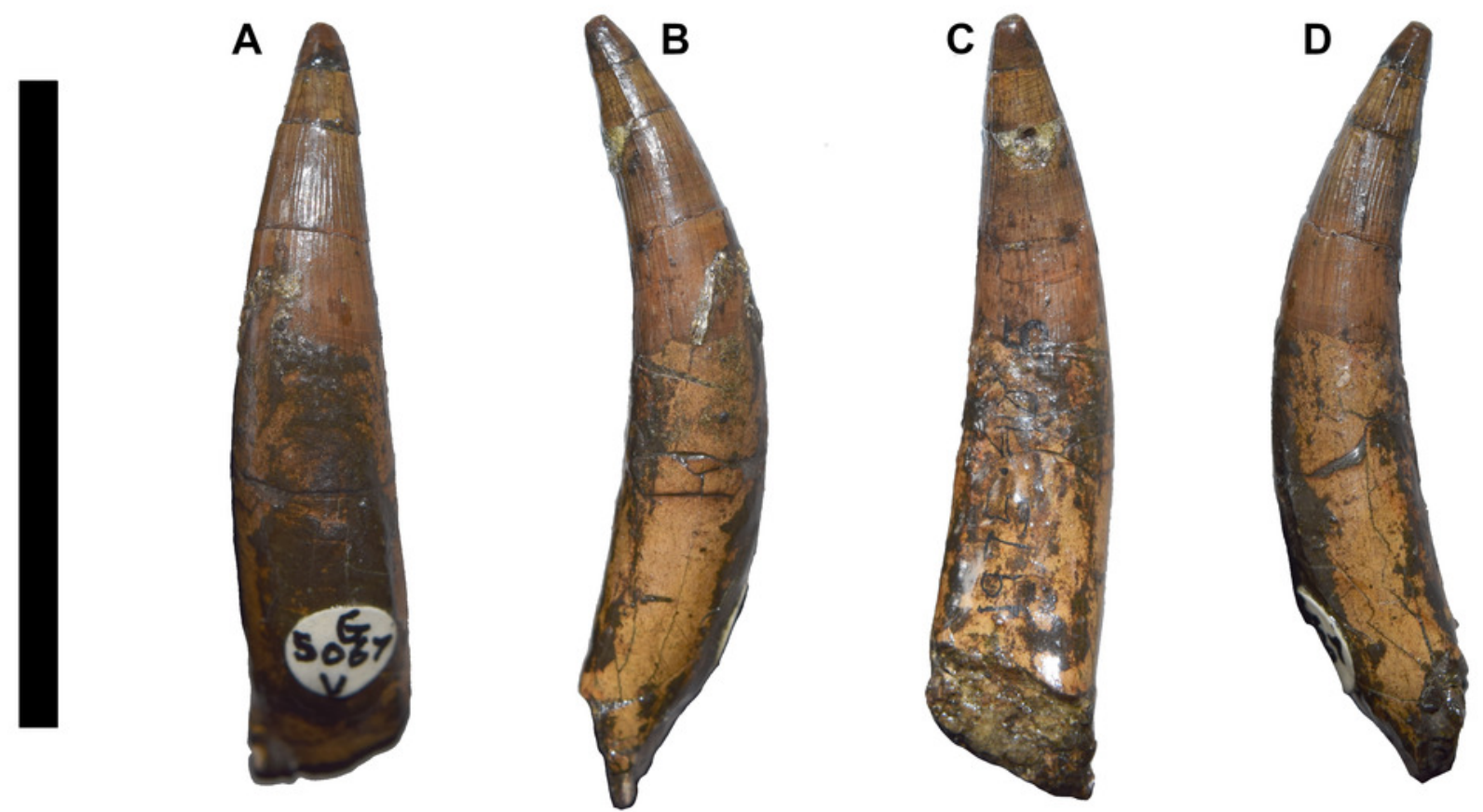


\section{Figure 8}

DORCM G.05067ii-iv osteoderms of Bathysuchus megarhinus gen. et. sp. nov.

A, Dorsal-sacral osteoderm DORCM G.05067ii in dorsal view. B, dorsal-sacral osteoderm DORCM G.05067ii in ventral view. C, caudal osteoderm DORCM G.05067iv in dorsal view. D, caudal osteoderm DORCM G.05067iv in ventral view. E, ventral osteoderm DORCM G.05067iii in view. F, ventral osteoderm DORCM G.05067iv in dorsal view. Scale bar equals $3 \mathrm{~cm}$.

A

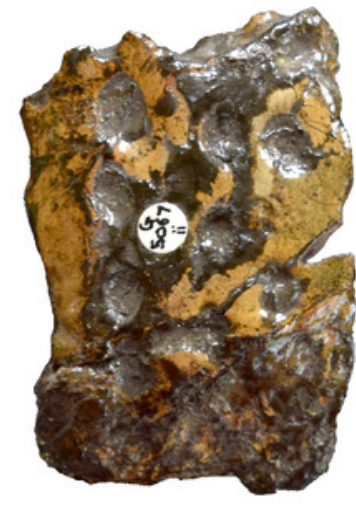

B

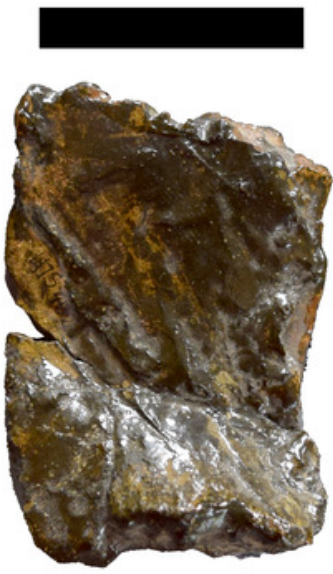

C
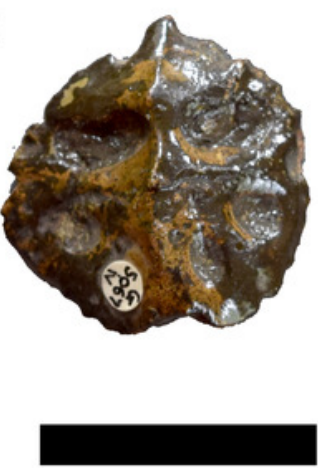

D

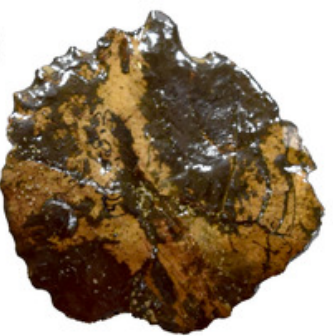

E
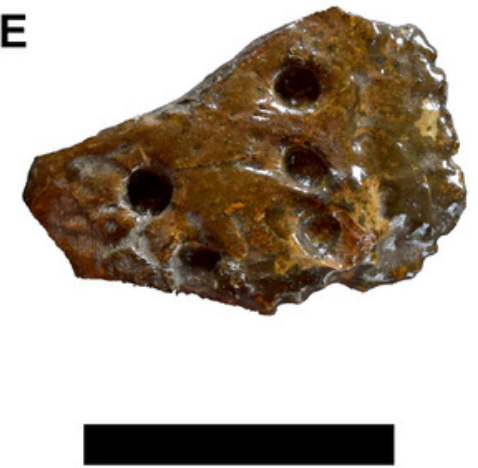

$\mathbf{F}$

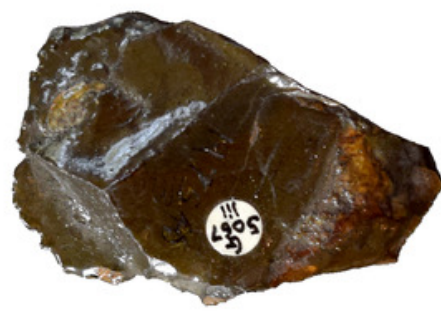


Figure 9

Comparative plate of selected teleosauroids premaxillae.

The left side of each diagram depicts the dorsal view, the right side the palatal view. Scale bar equals $5 \mathrm{~cm}$.

A

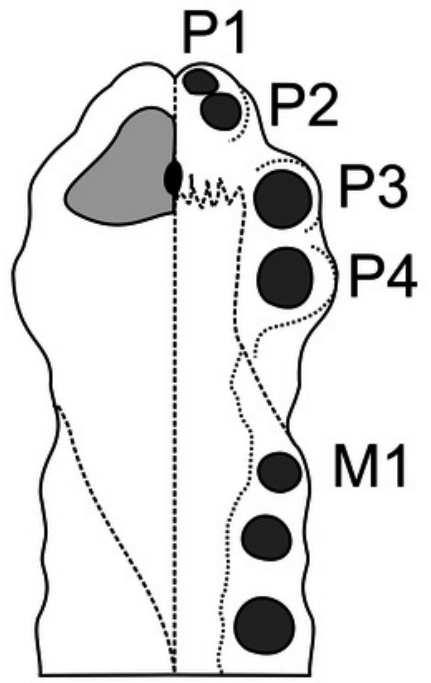

'Steneosaurus' leedsi
B

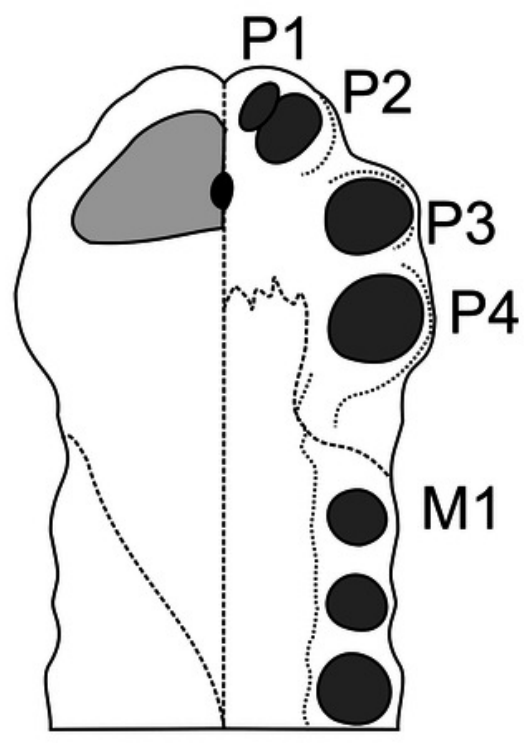

Steneosaurus edwardi

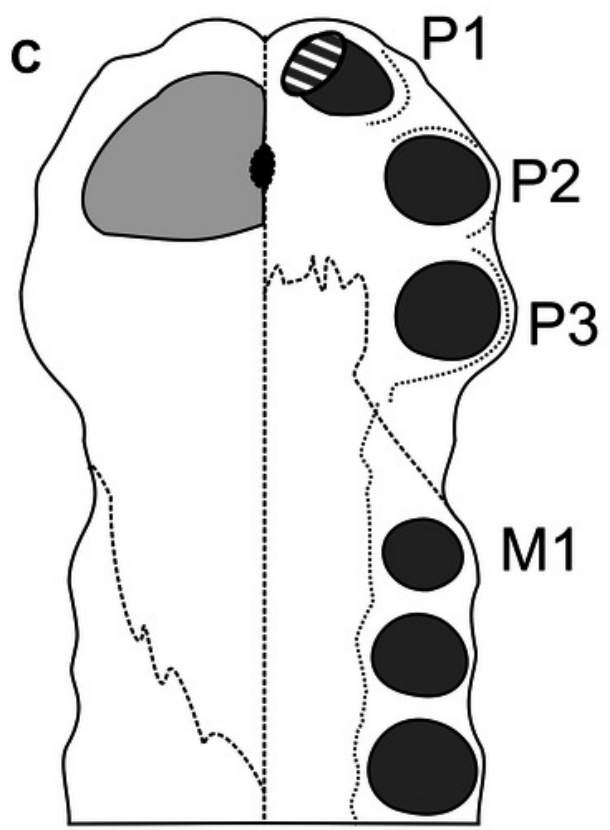

Machimosaurus

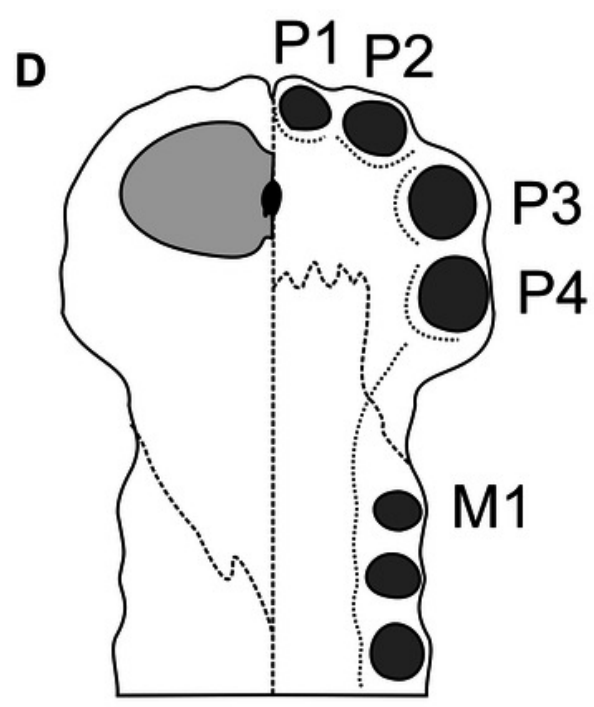

Mycterosuchus nasutus

Peer] reviewing PDF | (2018:02:25493:2:1:NEW 15 Feb 2019)
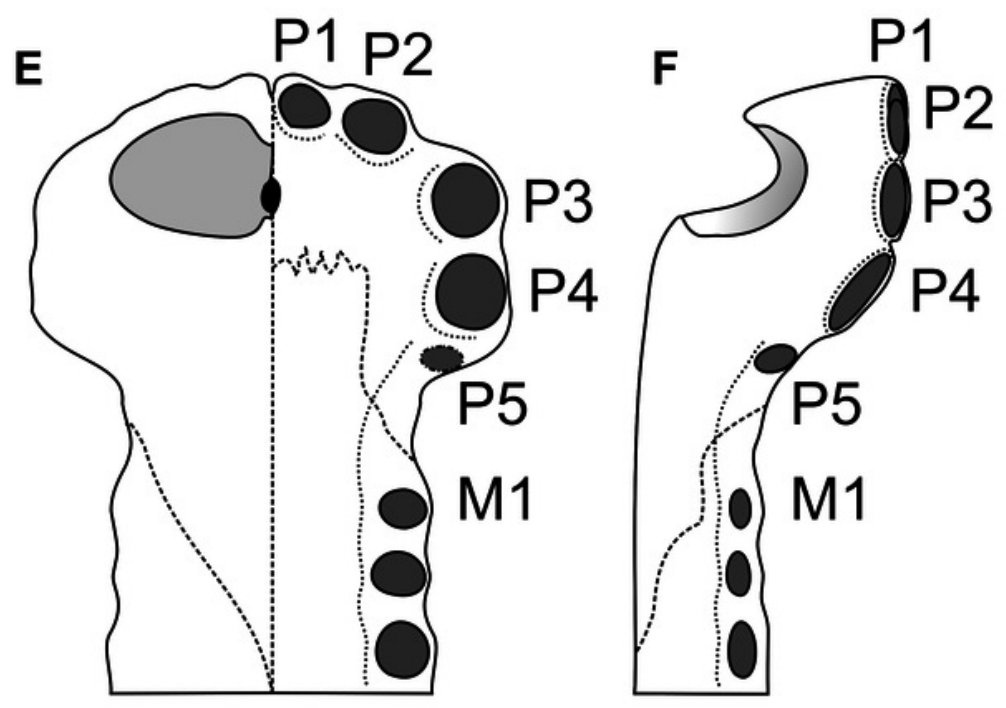

Bathysuchus megarhinus 


\section{Figure 10}

Aeolodon priscus MNHN.F.CNJ 78.

A, complete skeleton in dorsal view. $B$, dorsal region in dorsal view with details of the left forelimb and left hindlimb. C, details of the right forelimb. Scale bar in C equals $5 \mathrm{~cm}$.
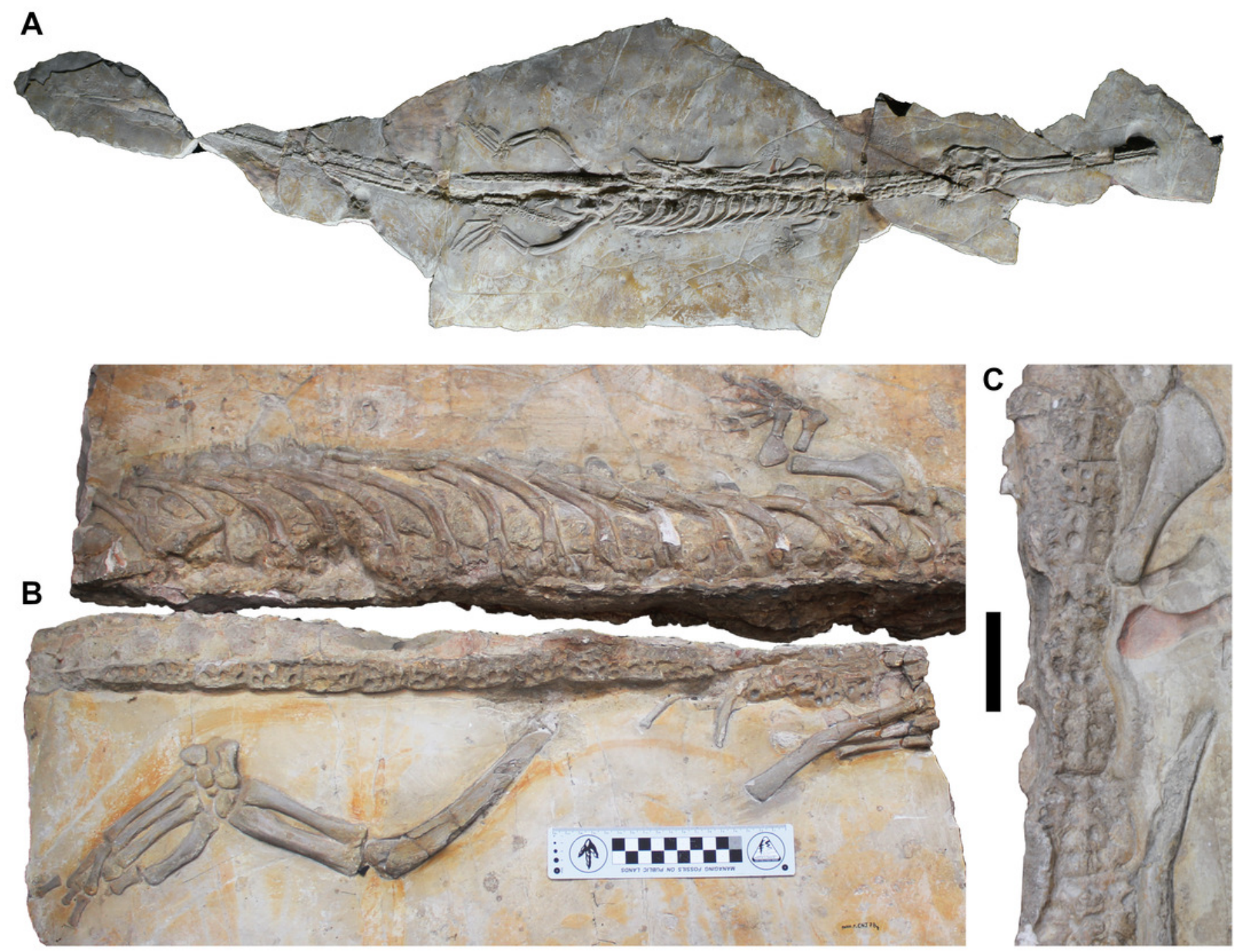


\section{Figure 11}

Comparative plate of selected teleosauroids premaxillae showing different degrees of skull and postcranial ornamentation.

A, 'Steneosaurus' leedsi NHMUK PV R 3806. B, Steneosaurus edwardsi NHMUK PV R 3701. C, Lemmysuchus obtusidens NHMUK PV R 3168. D, Machimosaurus buffetauti MPV V1600.Bo. E, Bathysuchus megarhinus DORCM G.05067i. F, G, H, Mycterosuchus nasutus CAMSM J.1420; F, premaxilla; G, orbital area; H, dorsal osteoderms. Scale bars equal $5 \mathrm{~cm}$.

A

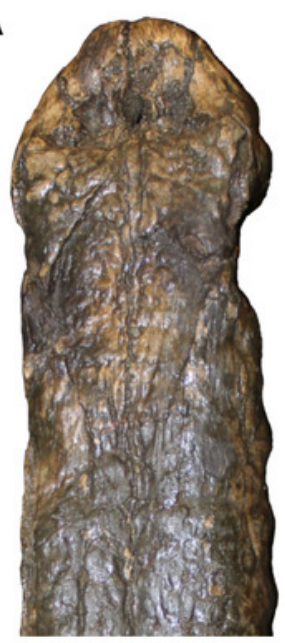

B

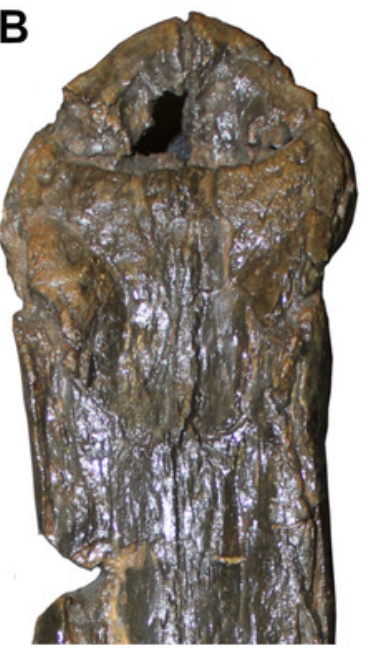

C

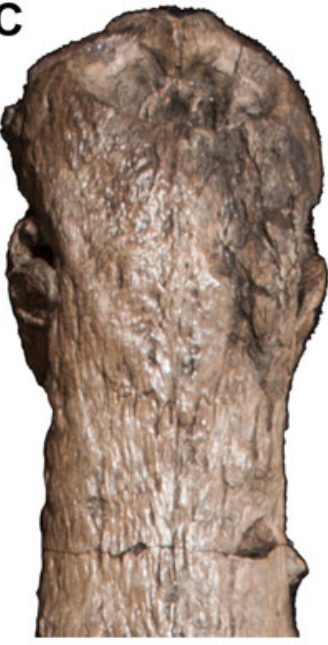

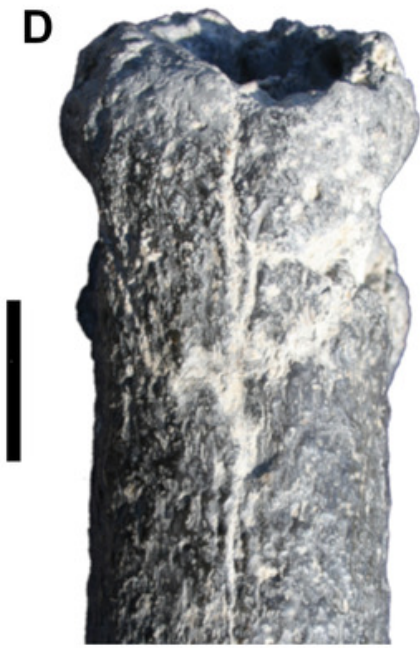
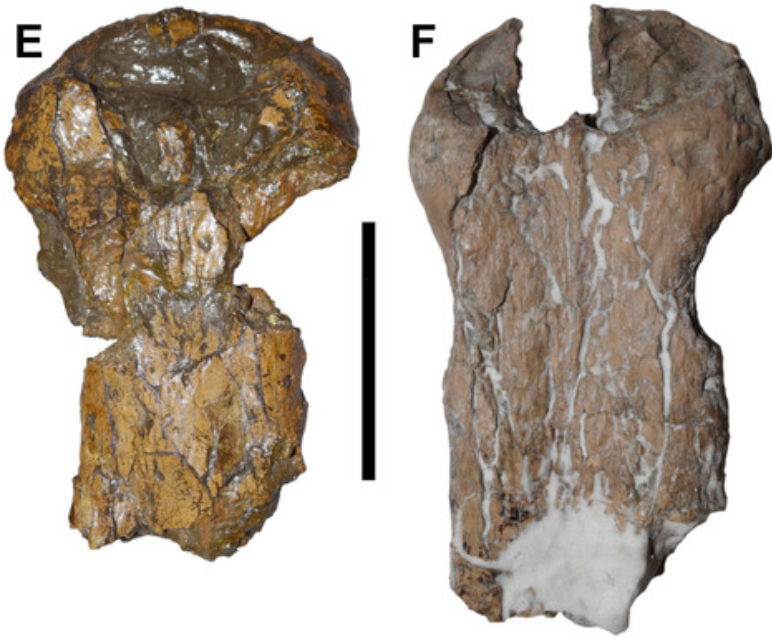

G
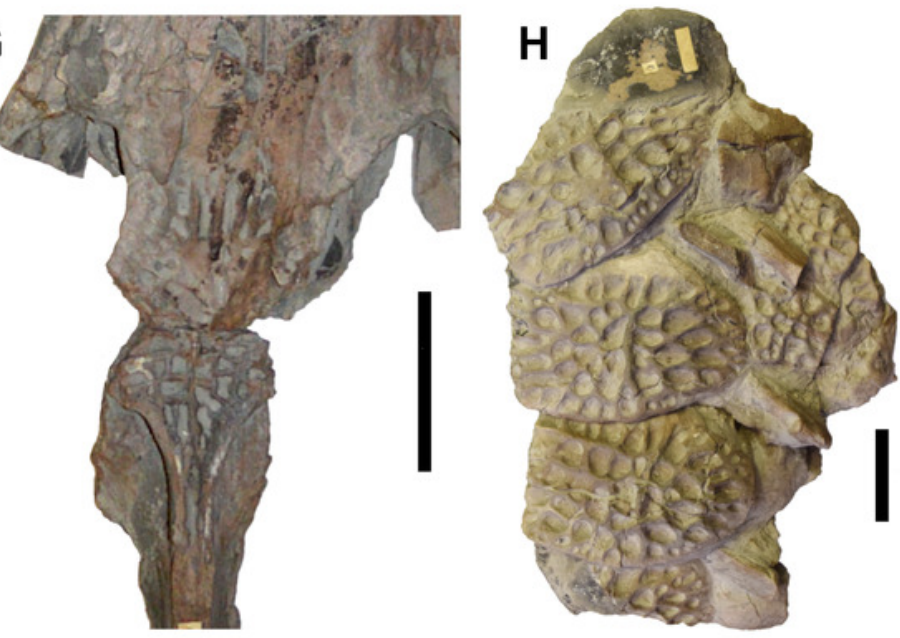
Figure 12

Results of the phylogenetic analysis.

Simplified strict consensus trees of the 85 most parsimonious cladograms of Teleosauroidea within Crocodylomorpha.

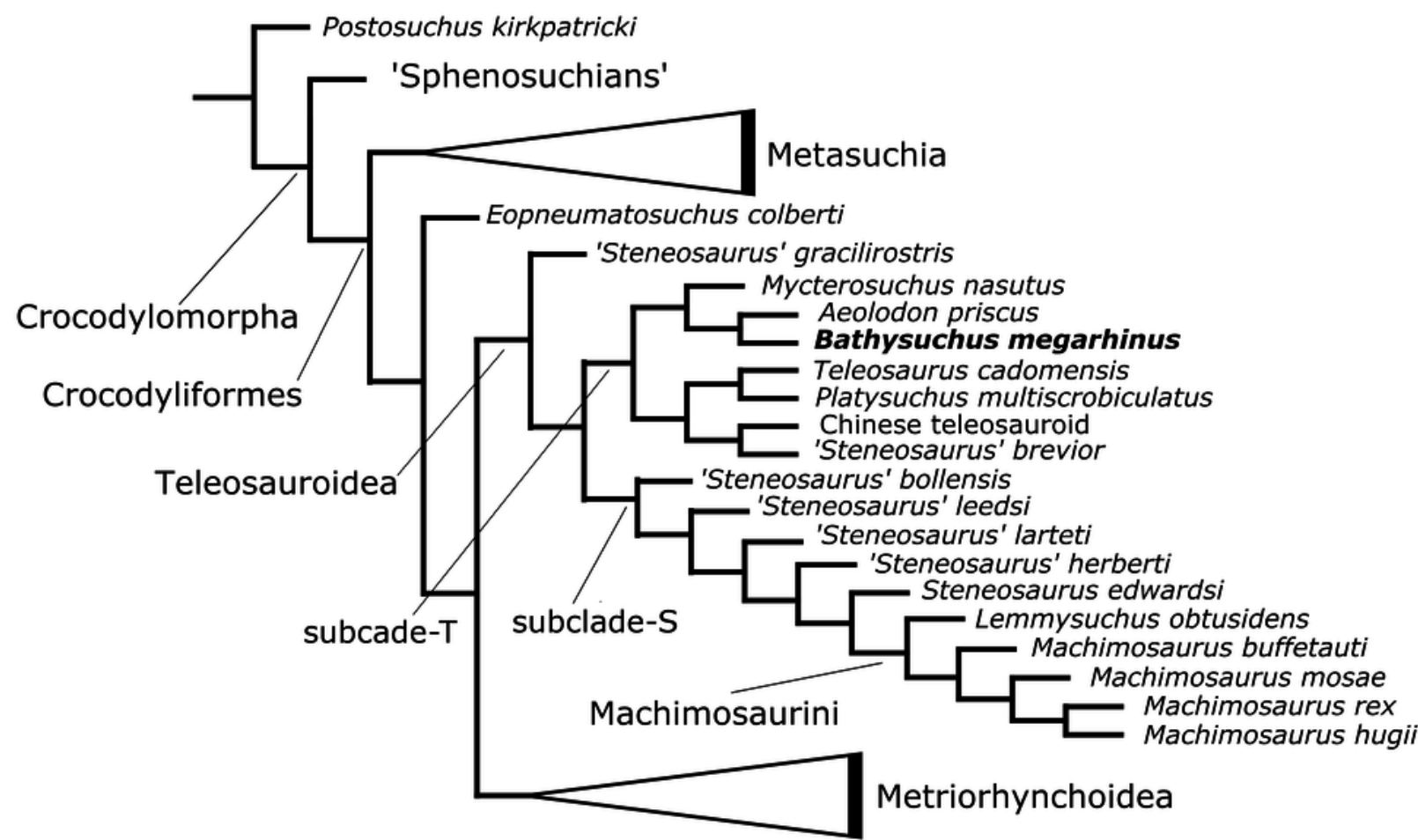




\section{Figure 13}

Scatter plots showing the limb proportions of Aeolodon priscus compared to other teleosauroids, metriorhynchoids and extant crocodylians.

$A$, humerus length vs femur length scatterplot, and $B$, known ranges of humerus:femur ratio in thalattosuchian and extant crocodylomorphs. C, Tibia length vs femur length scatterplot, and $D$, known ranges of Tibia:femur ratio in thalattosuchian and extant crocodylomorphs. The humerus:femur and tibia:femur ratios of Aeolodon priscus approaches those of fully pelagic metriorhynchids, in the low end of the known range of teleosauroids.* Indicates a juvenile specimen; each symbol represents a genus. 

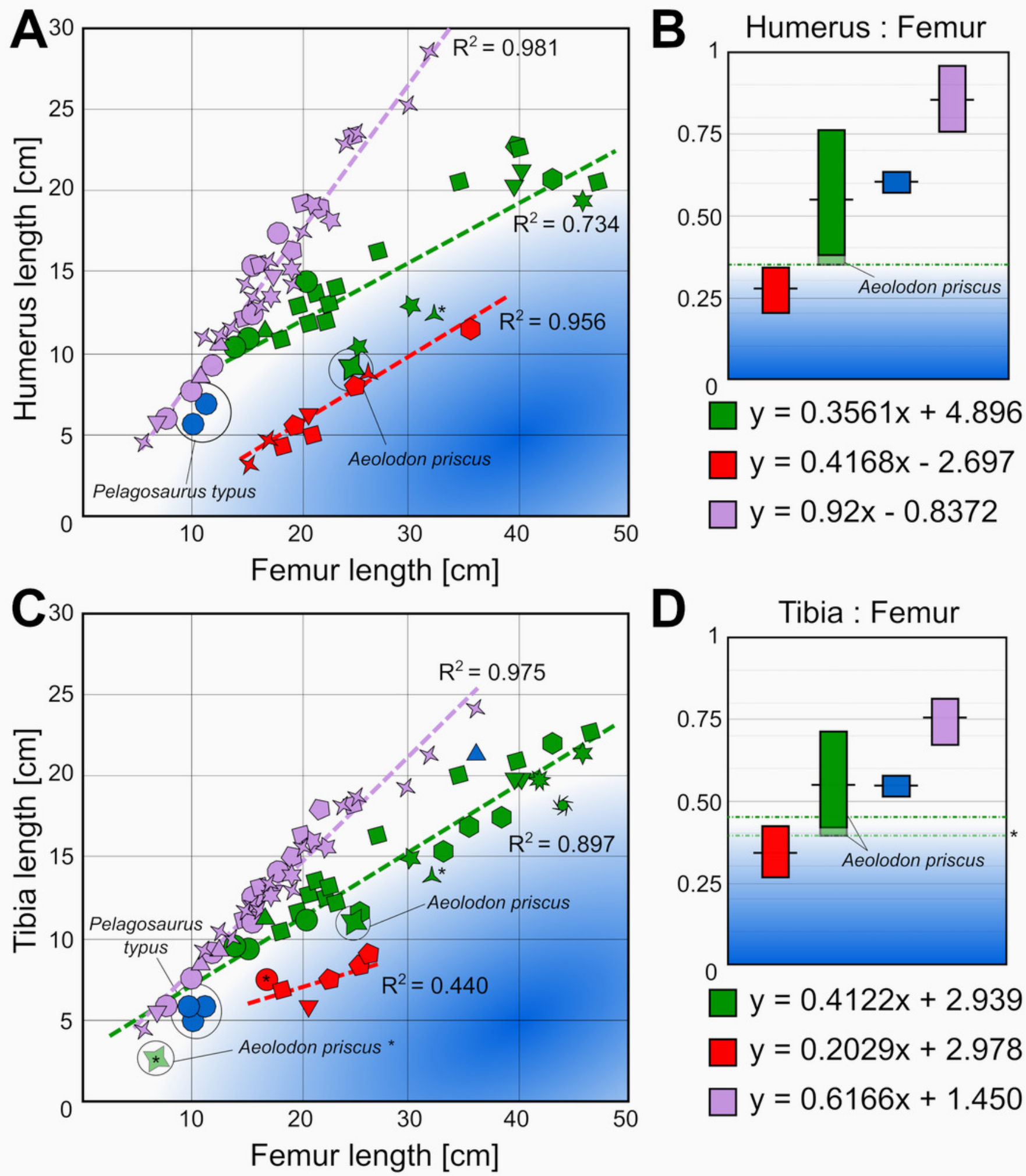

Teleosauroidea Basal metriorhynchoids 